\title{
Fuel and Chemical Properties of Waste Tire Pyrolysis Oil Derived from a Continuous Twin-Auger Reactor
}

\author{
Felipe Campuzano ${ }^{\text {a,b,c*, }}$, Abdul Gani Abdul Jameel ${ }^{\text {d, Wen Zhang }}{ }^{\mathrm{e}}$, Abdul-Hamid Emwas ${ }^{\mathrm{e}}$, Andrés F. \\ Agudelo $^{\text {b }}$ Juan Daniel Martínez a ${ }^{\text {, S. Mani Sarathy }}{ }^{\text {c* }^{*}}$ \\ ${ }^{a}$ Grupo de Investigaciones Ambientales (GIA), Universidad Pontificia Bolivariana (UPB), Circular $1^{r a} N^{\circ} 74-50$, Medellín, \\ Colombia. \\ ${ }^{b}$ Department of Mechanical Engineering, Universidad de Antioquia, Calle 67 Nº 53-108, Medellín, Colombia. \\ ${ }^{c}$ Clean Combustion Research Center (CCRC), King Abdullah University of Science and Technology (KAUST), Thuwal, Jeddah, \\ 23955-6900, Kingdom of Saudi Arabia. \\ ${ }^{d}$ Department of Chemical Engineering, King Fahd University of Petroleum \& Minerals, Dhahran 31261, Kingdom of Saudi \\ Arabia \\ ${ }^{e}$ Core Labs, King Abdullah University of Science and Technology (KAUST), Thuwal, 23955-6900, Kingdom of Saudi Arabia \\ *Corresponding author: \\ Felipe Campuzano <felipe.campuzano@udea.edu.co> \\ S. Mani Sarathy <mani.sarathy@kaust.edu.sa>
}

\begin{abstract}
Tire pyrolysis oil (TPO) is a complex mixture of hydrocarbons, and it is one of the useful fractions obtained from the pyrolysis of waste tires (WT). As a result of its high energy density (HHV 43 MJ/kg), TPO use as a fuel in combustion systems is a promising approach for recycling WT. However, fundamental fuel characteristics and combustion properties of TPO are still unexplored, which stand as a bottleneck for potential applications. This work pursues a comprehensive understanding of the structural characteristics of a TPO produced in a labscale twin-auger reactor as a first step towards defining applications and upgrading strategies. Therefore, advanced analytical techniques such as Fourier Transform - Ion Cyclotron Resonance Mass Spectrometry (FTICR MS), and ${ }^{1} \mathrm{H}$ and ${ }^{13} \mathrm{C}$ Nuclear Magnetic Resonance (NMR) spectroscopy were utilized. In addition, we also present the characterization of a TPO obtained from adding $\mathrm{CaO}$ to WT, as a low-cost catalytic material for its in-situ upgrading, herein named TPO[CaO]. FT-ICR MS results revealed the significant presence of pure hydrocarbons $(\mathrm{HC})\left(\mathrm{HC}_{(\mathrm{TPO})}=74.9 \%\right.$ and $\left.\mathrm{HC}_{(\mathrm{TPO}[\mathrm{CaO}])}=78.6 \%\right)$ and hydrocarbons containing one sulfur atom $\left(\mathrm{S}_{1}\right)\left(\mathrm{S}_{1(\mathrm{TPO})}=14.3 \%\right.$ and $\left.\mathrm{S}_{1(\mathrm{TPO}[\mathrm{CaO}])}=13.9 \%\right)$. HC compounds were found mainly in the form of tri-aromatics (26\%), tetra-aromatics (13 and $15 \%$ ), and penta-aromatics (22 and $30 \%$ ), while $\mathrm{S}_{1}$ compounds in the form of dibenzothiophene (31\%) and benzonaphthothiophene (34\%). The resolved compounds by means of FT-ICR
\end{abstract}


MS exhibited an average double bond equivalent (DBE) number of 11.3 and 12.2 for TPO and TPO[CaO], respectively. These high DBE values were indicators of the significant presence of condensed aromatic structures. ${ }^{1} \mathrm{H}$ NMR analysis showed that hydrogen atoms in methylene $\left(\mathrm{CH}_{2}\right)$, methyl $\left(\mathrm{CH}_{3}\right)$, and naphthenic groups, as well as hydrogen atoms in aromatic structures make up more than $80 \%$ of both fuels. Similarly, carbon atoms in paraffinic groups (both $\mathrm{CH}_{2}$ and $\mathrm{CH}_{3}$ ) and protonated carbons in aromatic rings together form more than $50 \%$ of the carbon atoms in TPO and TPO $[\mathrm{CaO}]$. The information reported in this work provides new insights into the structural characteristics of the TPO obtained in promising technology as the twin-auger reactor for its use as a fuel, as well as for the design of upgrading strategies.

Keywords: Tire pyrolysis oil, chemical structure, FT-ICR, NMR, average molecular parameters.

\section{Introduction}

Interest in the use of alternative fuels is growing, especially those obtained from non-edible sources and/or produced from waste, such as plastics and waste tires (WT) [1-3]. This is due to the vulnerability, environmental impact, and price variability of fossil fuels, as well as the added problem of disposing WT. The use of alternative fuels without any significant modification in combustion systems, referred to as drop-in fuels [4,5], has led to extensive research in the areas of fuel chemistry and fuel design, in order to develop advanced fuels [6-9]. There is an expanded search for new fuels from renewable or waste feedstock that can compete with petroleum-derived fuels. A detailed study of fuels from waste is therefore needed to find their best applications in targeted combustion systems [10].

Tire pyrolysis oil (TPO) is the liquid fraction obtained in the pyrolysis of WT. It contains a significant renewable portion due to the presence of natural rubber in tires [11]. Therefore, its use as fuel is in accordance with worldwide guidelines regarding the promotion of renewable energy, for instance the 2009/28/EC European directive. This suggests that TPO could be a suitable component in the variety of alternative fuels needed to supply the growing energy demand.

TPO is a dark-brown liquid containing a complex mixture of several hydrocarbon families with a wide carbon number range $\left(\mathrm{C}_{5}-\mathrm{C}_{50}\right)$, some heteroatoms including sulfur and nitrogen, as well as oxygen to a minor extent. 
Its $\mathrm{H} / \mathrm{C}$ atomic ratio is around 1.5 , which indicates the presence of both aliphatic (paraffins) and aromatic compounds [12,13]. This oil has high energy density (HHV: 40-44 MJ/kg), and physical and chemical properties comparable to those of crude oils, such as kinematic viscosity $(1.70-17.80 \mathrm{cSt})$ and density $\left(871-995 \mathrm{~kg} / \mathrm{m}^{3}\right)$ $[10,11,14-16]$. Elemental bulk carbon, hydrogen, nitrogen, sulfur and oxygen contents are usually in the range of 83-87 wt.\%, 9-11 wt.\%, 0.4-1 wt.\%, 0.6-1.4 wt.\%, 0.2-2.1 wt.\%, respectively, depending on feedstock composition and on pyrolysis conditions (temperature, residence time, etc.) [11]. TPO is a mixture of different hydrocarbon families with boiling points ranging from $70{ }^{\circ} \mathrm{C}$ to $450{ }^{\circ} \mathrm{C}$, or higher. Hita et al. [14] reported that TPO could be fractionated into $25.7 \mathrm{wt} . \%$ naphtha (boiling point $36-216^{\circ} \mathrm{C}$ ), $44.5 \mathrm{wt} . \%$ diesel (boiling point $216-343{ }^{\circ} \mathrm{C}$ ) and 29.8 wt.\% gasoil $\left(>343^{\circ} \mathrm{C}\right)$. This suggests that TPO can be considered as an unrefined hydrocarbon source [11]. Light aromatic hydrocarbons (benzene, toluene, xylene, and ethylbenzene), polyaromatic hydrocarbons (naphthalene), aliphatic hydrocarbons (dodecane, tridecane), and monoterpenes (limonene) seem to represent some of the major compounds in the mixture [17-20]. In general, yields and physicochemical properties of TPO are closely related to the tire composition, reactor technology, and main pyrolysis-governing variables (i.e. temperature, pressure, heating rate, residence time, etc.). Several works reported in literature associated with WT pyrolysis have aimed at developing a complete understanding about how these parameters influence TPO [11,12,15,21-25].

Among others, the combustion chemistry of a fuel depends on its molecular distribution and on its constituent functional groups $[26,27]$. As such, identifying and quantifying functional groups in the fuel helps in predicting its physical, chemical, and combustion properties, which are otherwise difficult to be experimentally measured [28]. Functional groups (determined by NMR spectroscopy [29]) are structural moieties that impart characteristic physical, chemical, and combustion properties to the molecule [26,30]. Likewise, structural characteristics such as the degree of branching (methylation) and the position of the branches in the molecule are defining contributors to the combustion reactivity (ignition delay) [26]. Abdul Jameel et al. [6] demonstrated the high negative impact of branching index (a structural parameter that quantifies the degree of branching by considering the number and position of the alkyl substitutions) on derived cetane number - DCN, and its positive influence on octane number [6]. Moreover, physical processes, such as spray formation and vaporization, are related to the molecular weight and molecular structure of the fuel. Alkyl substitutions also affect physical properties, such 
as boiling point and volatility. All these facts suggest that defining the structural characteristics is an important step in identifying and improving applications of alternative fuels [31]. In addition, the molecular analysis of fuels such as TPO is valuable for the advancement of scientific knowledge, and for obtaining accurate predictions of the combustion behavior through Quantitative Structure-Property Relationship (QSPR) based models [3234].

Due to the complex nature of TPO, unraveling its structural features has been a challenging undertaking. Despite its high energy density, much is not yet known about the structural properties influencing its combustion characteristics. Hence, a complete understanding of these characteristics is needed in order to provide new insights for its use in practical combustion applications, and for fuel upgrading strategies. As an example, different sulfur-containing compounds (one of the main drawbacks of TPO) behave differently when subjected to different desulfurization processes (i.e. oxidative desulfurization, hydrodesulfurization, extractive desulfurization, etc.) [35]. A proper understanding of the molecular characteristics of the sulfur-containing compounds present in TPO would help to select and optimize desulfurization steps. This knowledge will also be key to understanding gaseous and particulate matter emissions [8], as well as to define strategies to reduce TPO impacts on the environment and on human health. Thus, combustion and emission control systems could be either enhanced or modified to make TPO viable as a fuel for road transportation, marine transportation (low sulfur fuel oil), power generation (gas turbines/stationary diesel engines), or industrial applications (boilers) from a technical, economic, and environmental point of view.

The extent of knowledge regarding TPO's molecular structure is rather limited due to its complexity, which renders molecular resolution with conventional analytical techniques quite difficult. Fourier transform-infrared (FT-IR) spectroscopy has been used to identify functional groups and types of bonds in TPO molecules, hence revealing some chemical properties [36,37]. This technique allows not only a qualitative analysis, but also a semi-quantitative analysis, based on the area of the absorption bands appearing in a specific wavelength of the spectra [38]. However, it does not provide a broad description of the fuel. Gas chromatography coupled to mass spectroscopy (GC-MS) is a powerful analytical technique to analyze individual components in complex mixtures. This technique has been widely applied in TPO characterization [39]. Nevertheless, it requires an 
operational temperature of $300{ }^{\circ} \mathrm{C}$ or lower, due to the thermal stability limitations of the column's stationary phase [35]. Low to middle molecular weight compounds, including gas, naphtha, and middle distillates (kerosene, jet fuel, and diesel) can be detected by GC-MS. For higher boiling point fractions, many isomers remain partially or completely unresolved [35]. Hence, this technique is unable to completely analyze complex fuels like TPO, which contain high boiling point compounds.

High-resolution analytical techniques such as Fourier Transform Ion Cyclotron Resonance Mass Spectrometry (FT-ICR MS) and Nuclear Magnetic Resonance (NMR) are ideally suited to characterize complex and high molecular weight fuels that possess uncountable individual molecules, with the presence of heteroatoms. FTICR MS can resolve ions at the molecular level by assigning a unique elemental composition to each mass peak. It also detects extremely low mass differences at the order of one electron [40]. Samples are diluted by selected solvents, directly infused and then ionized by means of different ionization methods (i.e. atmospheric pressure photo ionization - APPI, electrospray ionization - ESI, atmospheric pressure chemical ionization - APCI, etc.) before being detected by FT-ICR MS. This technique has been reported in literature to study a number of samples such as base oil [41], heavy fuel oils [42], furnace oil [43], coal liquefaction products [44,45], microalgae biocrude oil [46], and lubricants [47], among others.

Likewise, ${ }^{1} \mathrm{H}$ and ${ }^{13} \mathrm{C}$ NMR are potential techniques to quantify the type of hydrogen and carbon atoms present in a fuel [48]. The information obtained from NMR can be used by itself or in combination with other data (e.g. elemental analysis and/or the average molecular weight obtained from FT-ICR MS) as an approach to estimate the overall/average molecular structure of complex mixtures [49]. This technique provides valuable information for predicting combustion characteristics and emissions. For instance, it has been widely used to predict fuel combustion properties by using molecular descriptors such as octane (RON and MON) [50] and cetane [6] numbers. Similarly, the structural information can be related to physical and chemical properties, as well as to kinetic parameters [26].

The information currently reported in the scientific literature does not provide a comprehensive characterization of TPO. Therefore, the aim of the present investigation is to understand the structural characteristics of TPO produced in a twin-auger reactor using a number of advanced analytical techniques such as APPI FT-ICR MS, 
${ }^{1} \mathrm{H}$ and ${ }^{13} \mathrm{C}$ NMR, and elemental analysis (CHNSO). Due to the relatively high sulfur content of TPO, a second TPO sample (TPO[CaO]) was produced with the addition of $\mathrm{CaO}$ during pyrolysis in order to test its potential for upgrading the fuel. This sample was then characterized using the same analytical techniques employed for TPO, in order to compare and contrast their structural characteristics.

\section{Materials and methods}

\subsection{Production of test fuels}

Two different fuel samples were assessed in this work, named as TPO and TPO[CaO]. Both samples were obtained in a continuous pyrolysis process conducted in a lab-scale twin-auger pyrolysis plant with a nominal capacity of $1 \mathrm{~kg} / \mathrm{h}$. TPO was produced by feeding WT granulate - a non-specified mixture of rubber without the steel thread and textile netting with a particle size between $2-4 \mathrm{~mm}$, provided by a Colombian tires recycling company — into the reactor. These granulate possess carbon, hydrogen, nitrogen, oxygen, and sulfur contents of 82.4 wt. $\%, 8.2$ wt. $\%,<0.1$ wt. $\%, 0.8$ wt. $\%$, and 1.9 wt. $\%$, respectively. In addition, WT also contain significant amounts of volatile matter (62.2 wt. \%, dry basis) and fixed carbon (29.9 wt. \%, dry basis) associated with rubber (both natural and synthetic) and several carbon blacks used in tire manufacture, respectively, and low content of ash (6.9 wt.\%, dry basis) linked to inorganic fillers. On the other hand, TPO[CaO] was obtained adding 15 wt. $\%$ of $\mathrm{CaO}$ with a particle size of $149-841 \mu \mathrm{m}$ in an independent and continuous manner during pyrolysis based on a fixed WT mass flow rate. In both cases, the experimental conditions were: $(i)$ pyrolysis temperature: $475^{\circ} \mathrm{C}$, (ii) residence time of the solids: $3.5 \mathrm{~min}$, (iii) mass flow rate of waste tires: $1.16 \mathrm{~kg} / \mathrm{h}$, and (iv) volumetric flow rate of $\mathrm{N}_{2}: 300 \mathrm{~mL} / \mathrm{min}$. These conditions were selected as those maximizing the yield of TPO, while keeping the volatile matter content in the recovered carbon black ( $\mathrm{rCB})$ as low as possible. A detailed description of the continuous twin-auger pyrolyzer, the pyrolysis experimental conditions, and the procedures to characterize the feedstock can be found in our previous work [51]. 


\subsection{Characterization of test fuels}

TPO and TPO $[\mathrm{CaO}]$ were initially characterized in terms of elemental composition using a Thermo Fischer Scientific 2000 apparatus, using lubricant oil (C: 82.07 wt.\%, H: 13.62 wt.\%, N:1.09 wt.\%, S: 3.22 wt.\%) as a standard for calibration. The initial characterization also included the determination of higher heating value (ASTM D240-17), density (ASTM D4052-11), kinematic viscosity (ASTM D445-12), water content (ASTM E203), and simulated distillation curve (ASTM D7500).

\subsubsection{APPI FT-ICR MS}

Mass spectrometry was conducted in a 9.4 Tesla SolariX FT-ICR MS (Bruker GmbH, Germany) equipped with an APPI source. Both TPO and TPO[CaO] were diluted in pure toluene and directly injected into the APPI source. The FT-ICR mass spectra of the samples were acquired using positive APPI ionization mode with a mass range of $154-1200 \mathrm{~m} / \mathrm{z}$. The APPI source uses a krypton light, which provides $10.6 \mathrm{eV}$ of ionization energy for the analytes; only singly charged ions were observed. The sample molecules were mainly ionized into molecular ions without undergoing fragmentation. The ion accumulation time in the hexapole was $0.01 \mathrm{~s}$, and each spectrum was acquired by accumulating 300 scans with a time domain size of 8 mega-points, and a transient length of $4.4739 \mathrm{~s}$. All mass spectra were externally calibrated using $0.05 \mathrm{mg} / \mathrm{ml}$ of a polystyrene solution (from 100 to $1200 \mathrm{~m} / \mathrm{z}$ ). Raw data was further recalibrated during data analysis using a set of homologous alkylated compounds for each sample. The mass list with signal to noise ratio $>5$ of each mass spectrum was generated by Data Analysis V4.5 and imported into the Composer software (Sierra Analytics, Pasadena, California, USA) for the assignment of chemical formulas [52]. With an error range of $0.5 \mathrm{ppm}$, the most likely elemental composition of each monoisotopic mass peak was calculated according to the determined accurate mass within the range of $\mathrm{C}_{1-100} \mathrm{H}_{1-200} \mathrm{~N}_{0-3} \mathrm{O}_{0-3} \mathrm{~S}_{0-3}$. Then, in order to achieve an overview of the compound distributions, all the assigned chemical formulas were divided into molecular classes (i.e. $\mathrm{HC}, \mathrm{S}_{1}, \mathrm{~S}_{2}, \mathrm{O}, \mathrm{N}$, etc.) according to the heteroatom content. The relative abundance of each molecular class was calculated as the total intensity of the particular class divided by the intensity of all assigned peaks. Based on the assigned molecular formula to each mass peak appearing in the spectrum, the double bond equivalent (DBE) number was calculated following 
Equation 1. The subscripts c, h, o, n, and s represent the number of carbon, hydrogen, oxygen, nitrogen, and sulfur atoms, respectively, in the assigned molecular formula $\left(\mathrm{C}_{\mathrm{c}} \mathrm{H}_{\mathrm{h}} \mathrm{N}_{\mathrm{n}} \mathrm{O}_{\mathrm{o}} \mathrm{S}_{\mathrm{s}}\right)$.

$$
\mathrm{DBE}=\mathrm{c}-\frac{\mathrm{h}}{2}+\frac{\mathrm{n}}{2}+1
$$

The average molecular weight $\left(\mathrm{MW}_{\text {avg }}\right)$ was determined by summing the product of $m / z\left(\mathrm{P}_{\mathrm{i}}\right)$ with the signal intensity $\left(\mathrm{I}_{\mathrm{i}}\right.$ ) of each recorded ion, then dividing by the total intensity of all the ions recorded (Equation 2). Similarly, the average number of carbons and the average DBE number were also calculated.

$$
\mathrm{MW}_{\mathrm{avg}}=\frac{\sum_{\mathrm{i}=1}^{\mathrm{n}} \mathrm{P}_{\mathrm{i}} \times \mathrm{I}_{\mathrm{i}}}{\sum_{\mathrm{i}=1}^{\mathrm{n}} \mathrm{I}_{\mathrm{i}}}
$$

\subsection{2 ${ }^{1} \mathrm{H}$ and ${ }^{13} \mathrm{C}$ NMR}

The solvent used was deuterated chloroform $\left(\mathrm{CDCl}_{3}\right) .50 \mu \mathrm{l}$ of the sample were diluted into $600 \mu \mathrm{l}$ of $\mathrm{CDCl}_{3}$. $0.6 \mathrm{ml}$ of the diluted mixture were transferred into $5 \mathrm{~mm}$ NMR tubes. A $700 \mathrm{MHz}$ Bruker AVANCE III spectrometer was used to obtain the spectra at $298 \mathrm{~K}$. The spectrometer was equipped with a Bruker CP TCI

multinuclear CryoProbe (from Brukerbiospin, Rheinstetten, Germany). In order to record the ${ }^{1} \mathrm{H}$ NMR spectra, 128 scans were collected with a recycle delay time of $10 \mathrm{~s}$. A standard one-dimensional (1D) $90^{\circ}$ pulse sequence was used with standard (zg) program from the Bruker pulse library. Tetramethylsilane (TMS) was used as the internal chemical shift reference for both ${ }^{1} \mathrm{H}$ and ${ }^{13} \mathrm{C}$ spectra. A spectral width of $14,098 \mathrm{~Hz}$ was digitized into 64,000 data points to collect the free induction decay (FID). In order to record the ${ }^{13} \mathrm{C}$ NMR spectra, a 1D sequence was used with power gate decoupling, along with a $30^{\circ}$ flip angle, using the standard $1 \mathrm{D}$ pulse sequence zgig30 program from the Bruker pulse library. Fourier transformation was applied after applying a line broadening of $1 \mathrm{~Hz}$. Bruker Topspin 4.0.4 software (Bruker BioSpin, Rheinstetten, Germany) was used to collect the spectra and MestreNova was used for both spectral post-processing and for data analyses.

\subsubsection{Average molecular parameters (AMPs)}

AMPs enable the structural elucidation of complex hydrocarbon fuels. They are obtained by combining the NMR data with elemental analysis and the average molecular weight (determined from FT-ICR MS). This method 
provides the total distribution of both carbon (from ${ }^{13} \mathrm{C}$ NMR) and hydrogen $\left({ }^{1} \mathrm{H} \mathrm{NMR}\right)$ atoms in a fictitious average molecule of the fuel (i.e., number of carbon and hydrogen atoms in paraffinic, naphthenic, olefinic, aromatic, etc., compounds) [53]. The NMR spectra is represented in terms of the chemical shifts (usually given in terms of ppm), which is associated with the resonant frequency of the nuclei relative to a magnetic field. Different nuclei exhibit different shifts, and the splitting pattern along with the position of these shifts shed light into the molecular structure. ${ }^{1} \mathrm{H}$ NMR spectra have a typical chemical shift range between 0 and $+14 \mathrm{ppm}$, while ${ }^{13} \mathrm{C}$ NMR spectra have a larger chemical shift range between 0 and $+220 \mathrm{ppm}$. Specific regions within the spectra can be assigned to a group of nuclei. For instance, hydrogen atoms in poly-aromatic compounds give rise to signals between 7.20-8.99 ppm, while hydrogen atoms in paraffinic $\mathrm{CH}_{3}$ groups lie between 0-0.97 ppm. Similarly, carbon atoms in aromatic quaternary compounds produce peaks between 140.5-160.0 ppm, while paraffinic quaternary carbon atoms do so between 50.0-60.0 ppm [49]. NMR spectroscopy is an inherently quantitative technique, as the area under each peak (integral) is proportional to the concentration level and the number of these nuclei in each molecule existing in the mixture sample.

An AMP can be determined by means of Equation 3. X refers to either $\mathrm{C}$ or $\mathrm{H}$ atoms, I denotes ${ }^{1} \mathrm{H}$ or ${ }^{13} \mathrm{C}$ NMR integral area, and index i refers to a particular chemical shift interval in the NMR spectra. \% X stands for the weight percent of $\mathrm{X}$ from the elemental composition.

$$
\mathrm{X}_{\mathrm{i}}=\frac{\mathrm{I}_{\mathrm{i}}}{\mathrm{I}_{\text {Total }}} \% \mathrm{X}
$$

The average molecular formula of TPO and TPO $[\mathrm{CaO}]$ can be obtained in the form of $\mathrm{C}_{\mathrm{c}} \mathrm{H}_{\mathrm{h}} \mathrm{O}_{\mathrm{o}} \mathrm{N}_{\mathrm{n}} \mathrm{S}_{\mathrm{s}}$, where the subscripts c, h, o, n, and s represent the respective number of atoms (see Equation 1) in the hypothetical molecule. The number of these atoms can be calculated following Equation 4:

$$
\text { Number of Atoms }=\mathrm{MW}_{\mathrm{avg}} \times \% \mathrm{X}\left(\frac{1}{100 \times \mathrm{a}_{\mathrm{y}}}\right)
$$

$\mathrm{MW}_{\text {avg }}$ is the average molecular weight of the sample, obtained by means of APPI FT-ICR MS. From Equation 2, \% X is the weight percent of the respective element $(\mathrm{C}, \mathrm{H}, \mathrm{N}, \mathrm{S}, \mathrm{O})$ obtained from the elemental analysis, and $\mathrm{a}_{\mathrm{y}}$ is the atomic mass of the respective element, in grams per mole. The chemical shift assignments and the 
nomenclature used for denoting the symbols in this work were chosen following the methodology proposed by Poveda and Molina [31]. Derived AMPs, such as aromaticity factor (fa), $\mathrm{C} / \mathrm{H}$ ratio, average chain length ( $\mathrm{n}_{\text {acl }}$ ), naphthenic ring number $\left(\mathrm{R}_{\mathrm{N}}\right)$, aromatic ring number $\left(\mathrm{R}_{\mathrm{A}}\right)$, and aromatic condensation index $(\phi)$ were also calculated. These derived AMPs provide additional information on the atomic arrangement within TPO and $\mathrm{TPO}[\mathrm{CaO}]$ structures. The formulae and the procedure to calculate these derived AMPs are described elsewhere [49].

\section{Results and discussion}

\subsection{Physicochemical properties}

Table 1 presents the elemental composition, some physical properties (API gravity, viscosity, density) including the heating value, and some distillation parameters of TPO and TPO $[\mathrm{CaO}]$. Both fuel samples have high carbon (86.64 and 87.21 wt.\%) and hydrogen (10.56 and 10.66 wt.\%) contents, which agree with the information reported previously in the literature related to TPO obtained from different types of pyrolyzers and processing conditions $[10,11,14,15,37]$. The high sulfur content in TPO and TPO $[\mathrm{CaO}](0.69$ and $0.51 \mathrm{wt} \%$, respectively) is one of their main drawbacks. Even though these values are significantly smaller compared to that of heavy fuel oils used in the marine sector [54], they are high enough to pose detrimental effects on human health and on the formation of acid rain. For instance, and according to the Regulation 14.1.3, MARPOL Annex 14 [55], by 2020 all ships should burn fuels with a sulfur content of no more than $0.5 \mathrm{wt} . \%$. Moreover, environmental limits related to $\mathrm{SO}_{2}, \mathrm{NO}_{2}$, and $\mathrm{CO}$ emissions levels established by the European Air Quality Standard (EU2015/2193), have restricted the use of TPO in automotive engines. Thus, upgrading strategies, in particular deep desulfurization methods $[56,57,66,58-65]$ are required before the use of TPO in this application. After vulcanization, sulfur in rubber may be present in the form of monosulfide, disulfide, or polysulfide, as well as cyclic-mono- and di-sulfides. During pyrolysis, the decomposition of these sulfur-containing compounds, coupled with the influence of the high temperature, gives rise to the formation of aromatic structures containing sulfur atoms, some of which will be found in TPO [67]. These structures will be visualized with the FT-ICR MS results in Section 3.2.1. 
Table 1. Basic physicochemical properties of TPO and TPO[CaO]

\begin{tabular}{llll}
\hline Property/ Sample & Methods & TPO & TPO $[$ CaO] \\
\hline $\mathrm{C}($ wt.\%) & & 86.64 & 87.21 \\
$\mathrm{H}($ wt.\%) & ThermoScientific 2000 & 10.56 & 10.66 \\
$\mathrm{~N}($ wt.\%) & apparatus & 1.32 & 1.23 \\
$\mathrm{~S}($ wt.\%) & & 0.69 & 0.51 \\
$\mathrm{O}($ wt.\%) & & 0.78 & 0.39 \\
$\mathrm{H} / \mathrm{C}$ & from elemental analysis & 1.46 & 1.47 \\
\hline API gravity & & 29.70 & 29.70 \\
Viscosity $40{ }^{\circ} \mathrm{C}(\mathrm{cSt})$ & ASTM D445-12 & $2.60 \pm 0.4$ & $1.90 \pm 0.4$ \\
Density $15{ }^{\circ} \mathrm{C}\left(\mathrm{kg} / \mathrm{m}^{3}\right)$ & ASTM D4052-11 & 888.29 & 888.67 \\
High Heating Value $(\mathrm{MJ} / \mathrm{kg})$ & ASTM D240-17 & 42.76 & 43.40 \\
\hline Initial BP $\left({ }^{\circ} \mathrm{C}\right)$ & ASTM D86 & 69.00 & 70.00 \\
$50 \%$ distillation $\left({ }^{\circ} \mathrm{C}\right)$ & ASTM D7500 & 253.90 & 253.90 \\
$90 \%$ distillation $\left({ }^{\circ} \mathrm{C}\right)$ & ASTM D7500 & 433.60 & 429.50 \\
Final BP $\left({ }^{\circ} \mathrm{C}\right)$ & ASTM D7500 & 558.50 & 550.90 \\
\hline
\end{tabular}

Properties such as viscosity, density, heating value, and distillation have a significant influence on combustion. Density and viscosity affect the formation of spray droplets, hence influencing the overall fuel evaporation and distribution in internal combustion engines [10]. ТPO[CaO] presents a slightly lower kinematic viscosity $(1.9 \pm$ $0.4 \mathrm{cSt})$ than TPO $(2.6 \pm 0.4 \mathrm{cSt})$. The lower viscosity of TPO $[\mathrm{CaO}]$ could be attributed to the catalytic effect of $\mathrm{CaO}$ during the pyrolysis, where it is likely that the heavy/long chain hydrocarbons underwent cracking. The cracking effect of $\mathrm{CaO}$ arises from the ability of $\mathrm{O}^{2-}$ to destabilize the $\pi$-electron cloud resonance structure of aromatic rings, as well as to abstract $\mathrm{H}^{+}$ions [68-71]. In addition, viscosity has been shown to directly correlate with sulfur content in fuels [27]. In this regard, the lower sulfur content of TPO[CaO], in contrast to TPO, may have given rise to its lower viscosity. A reduction in viscosity effectively translates into improved atomization for the liquid spray. As such, smaller fuel droplets can undergo a more thorough burnout for a fixed residence time. A smaller droplet size increases combustion efficiency, while reducing total hydrocarbon (THC), $\mathrm{CO}$ and particulate matter (PM) emissions [72,73]. API gravity is used to classify an oil as light (> 31.1), medium (22.3 - 31.1), heavy (<22.3), and extra heavy $(<10)$. As the "weight" of the oil is the largest determinant of its market value, API gravity is an important parameter [74]. API gravity was found to be 29.7 for both samples. According to this, TPO and TPO[CaO] can be classified as medium weight oil. In general, all of the above-mentioned properties are similar to those reported for conventional fuels. Therefore, a deeper knowledge of the TPO chemistry is fundamental, in order to understand and explain its combustion properties.

Distillation characteristics affect the fuel/air mixture formation, as well as the ignition and combustion processes. These characteristics are based on the volatility of fuel, which can be related to its molecular size and structure. 
The measured initial boiling point suggests that both samples contain light compounds that evaporate and mix easily with air. Moreover, high volatility has a significant influence on flash point, given the formation of fuel vapor/air mixture that can be ignited easily. The distillation temperature at which $50 \%$ of the fuel is evaporated $\left(\mathrm{T}_{50}\right)$ was the same for both fuels. This parameter is a broad indicator of warm-up and acceleration performance under cold starting conditions in internal combustion engines [75]. The lower the $\mathrm{T}_{50}$ of the fuel, the better the performance of this type of oils in engines [76]. Similarly, when the distillation temperature at which $90 \%$ of the fuel is evaporated $\left(\mathrm{T}_{90}\right)$, and the final distillation point are high $\left(>350^{\circ} \mathrm{C}\right)$, poor ignition distribution may occur in the combustion chamber. This leads to the increase of THC emissions and excessive combustion chamber deposits. Assuming similar atomization quality, a fuel with low volatility tends to form localized regions in the reaction zone, with a lower equivalence ratio than the nominal value. The net result is a reduced rate of heat release that promotes the onset of flame extinction and blow-out at higher overall equivalence ratios than more volatile fuels [77].

In contrast to conventional fuels, $\mathrm{T}_{50}$ and $\mathrm{T}_{90}$ are significantly high for both $\mathrm{TPO}$ samples, which can be associated with the presence of high molecular weight compounds, such as polycyclic aromatic hydrocarbons (PAH) and polycyclic aromatic sulfur hydrocarbon (PASH) $[18,37,78]$. The structural level characterization of TPO has revealed the significant presence of condensed aromatic structures of increasing size, up to three ring PAH [79]. Likewise, sulfur-containing compounds have been identified in the form of benzothiophenes and dibenzothiophenes [78]. These compounds present high molecular weight (above $420 \mathrm{~g} / \mathrm{mol}$ ), and a wide range of carbon atoms number (between 10 and 55). These characteristics will be discussed in the following sections.

\subsection{Structural characterization of TPO and TPO $[\mathrm{CaO}]$}

\subsubsection{APPI FT-ICR MS}

APPI FT-ICR MS was used in this work to study the chemical composition and molecular structure of TPO and $\mathrm{TPO}[\mathrm{CaO}]$. Based on the unsaturation degree and carbon range distribution, structural parameters were elucidated. Even though there are different ionization modes, APPI mode was chosen in this work as it is more effective in ionizing high aromatic and sulfur containing compounds [41]. Fig. 1 shows the mass spectra obtained 
for each sample. The mass spectra of TPO and TPO $[\mathrm{CaO}]$ exhibit a mass to charge ratio $(\mathrm{m} / \mathrm{z})$ ranging from 200 to 800 , and from 200 to 750 , respectively. Herein, 2,448 and 1,473 mass peaks were resolved for TPO and $\mathrm{TPO}[\mathrm{CaO}]$, respectively, and a unique molecular formula was assigned to each mass peak detected. Due to the high complexity of TPOs, the possible structural isomers with identical chemical formulas and molecular weights cannot be distinguished by FT-ICR MS technique alone [79]. Nevertheless, comparing with other classic analytical methods, such as FT IR, NMR, etc., FT-ICR MS technique can provide the most detailed compositional and structural information of complex oil samples at the molecular level. The inserted graphs (histograms) in Fig. 1 show the frequency at which the resolved compounds for either TPO or TPO[CaO] fall in a specific $\mathrm{m} / \mathrm{z}$ range. As such, it can be observed that in both cases, the highest frequency is found in a $\mathrm{m} / \mathrm{z}$ range between 400 and 450 . Moreover, the symmetrical shape of the continuous lines shows values clustering around the central range (normal distribution); thus, the $\mathrm{MW}_{\mathrm{avg}}$ was calculated to lie in this range as shown later.

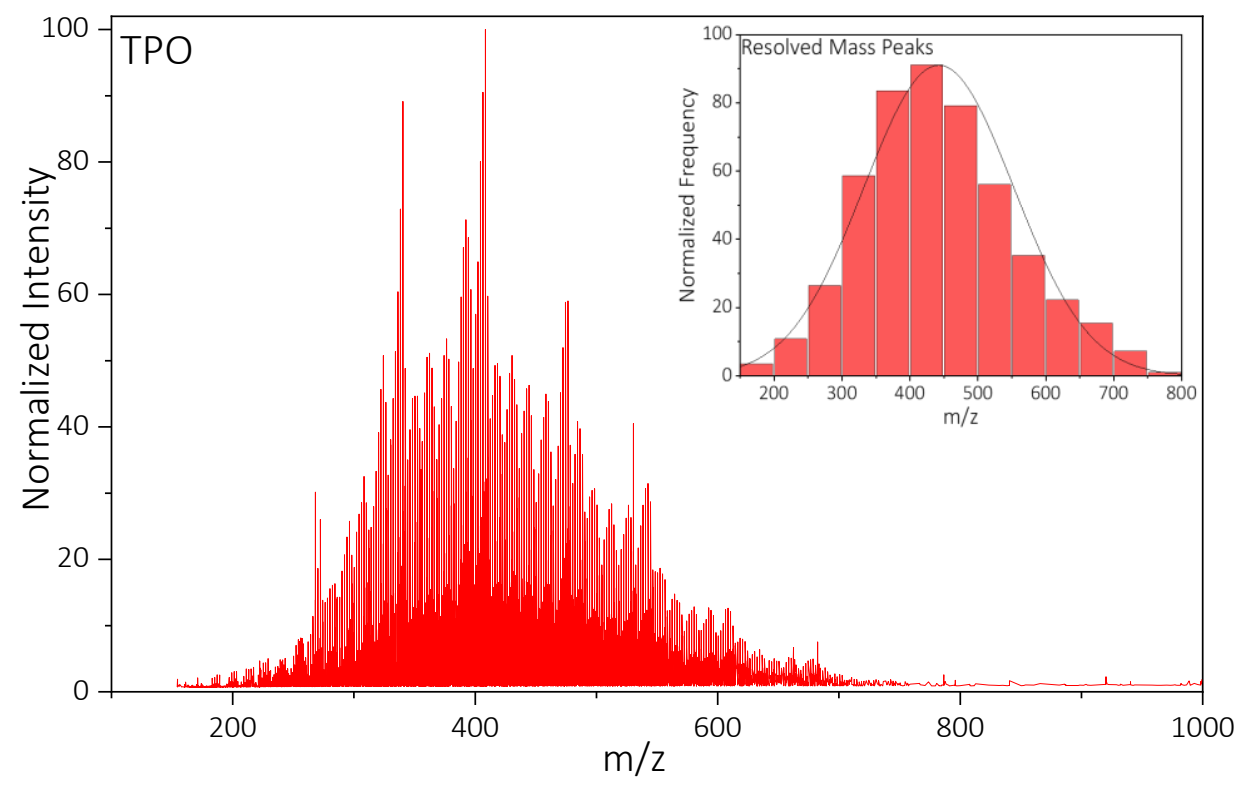




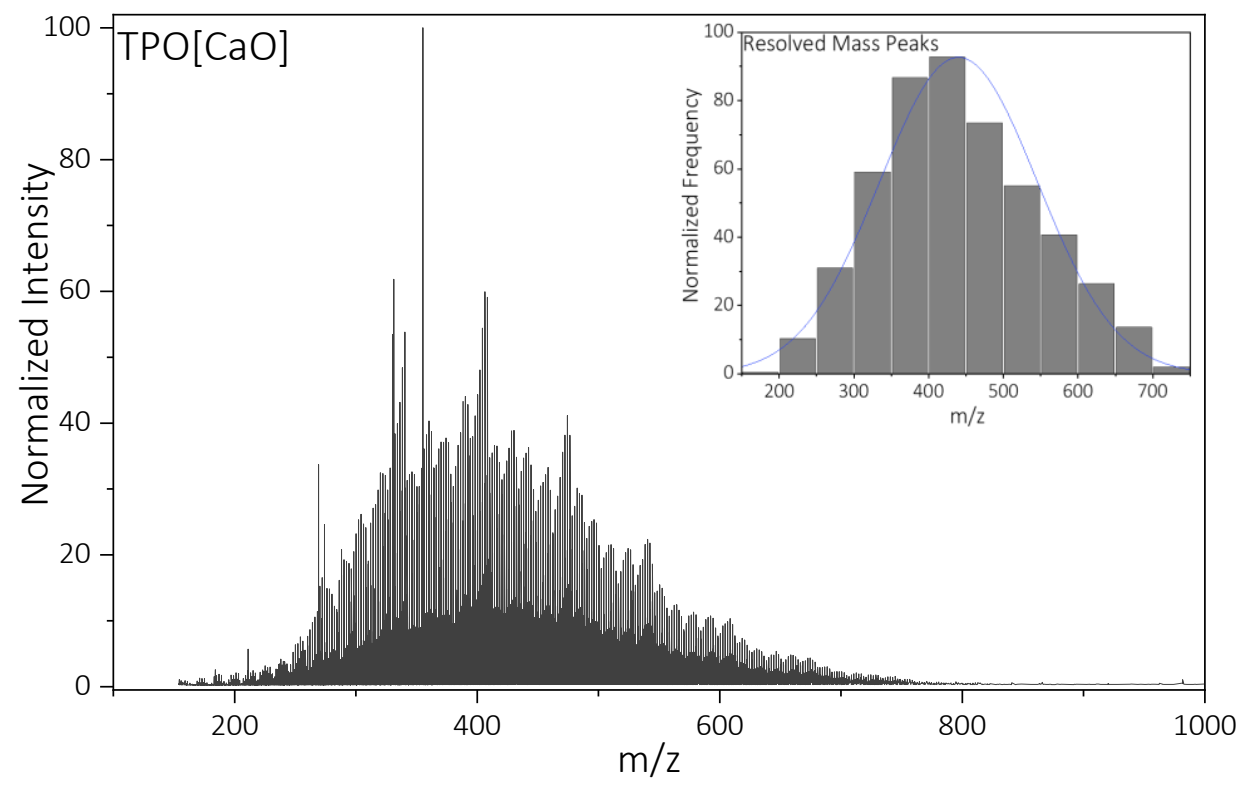

Fig. 1. APPI FT-ICR mass spectra of TPO and TPO[CaO]

Table 2 presents some molecular parameters for TPO and TPO[CaO], derived from the assigned chemical formulas. The following values were calculated: $\mathrm{MW}_{\mathrm{avg}}$, the average number of carbon atoms $\left(\mathrm{C}_{\mathrm{avg}}\right)$, and the average DBE number $\left(\mathrm{DBE}_{\text {avg }}\right.$ ). The $\mathrm{MW}_{\text {avg }}$ was found to be 430 and $427 \mathrm{~g} / \mathrm{mol}$ for TPO and TPO[CaO], respectively. These values, along with the average number of carbon atoms (31.6) agree with the high final boiling points $\left(558.5\right.$ and $550.9^{\circ} \mathrm{C}$ ) of TPO and TPO[CaO], previously reported in Table 1. It is important to point out that the oil obtained from WT presents a significant content of low molecular weight hydrocarbons such as benzene $\left(\mathrm{C}_{6}\right)$, toluene $\left(\mathrm{C}_{7}\right)$, xylene $\left(\mathrm{C}_{8}\right)$, limonene $\left(\mathrm{C}_{10}\right)$, etc., which explains the low initial boiling point (69 and $70{ }^{\circ} \mathrm{C}$ for TPO and TPO[CaO], respectively) $[11,14]$. However, these compounds are not detected by the present technique. Light hydrocarbons have low molecular weight, which makes them travel very fast in the ICR cell with possible interference of signals that make accurate determination difficult [80]. These compounds are more suitable to be detected by GC-MS.

Table 2. Average molecular parameters

\begin{tabular}{lll}
\hline Parameter & TPO & TPO[CaO] \\
\hline $\mathrm{MW}_{\text {avg }}(\mathrm{g} / \mathrm{mol})$ & 430 & 427 \\
Carbon number range & $12-56$ & $14-53$ \\
$\mathrm{C}_{\text {avg }}$ & 31.6 & 31.6 \\
DBE number range & $0.5-27$ & $4-26$ \\
$\mathrm{DBE}_{\text {avg }}$ & 11.3 & 12.2 \\
$\mathrm{H} / \mathrm{C}$ & 1.46 & 1.46 \\
\hline
\end{tabular}


The calculation of the DBE number is a well-established tool in mass spectrometry, especially for the analysis of complex mixtures, such as petroleum and dissolved organic matter. It represents the sum of unsaturated bonds plus rings in a molecule. The $\mathrm{DBE}_{\text {avg }}$ for TPO and TPO$[\mathrm{CaO}]$ were found to be 11.3 and 12.2, respectively. An earlier work conducted by Hita et al. [61] reported that TPO can be divided into 2.39 wt.\% paraffins, 7.11 wt.\% olefins, $34.37 \mathrm{wt} . \%$ naphthenes and $55.83 \mathrm{wt} . \%$ aromatics. Taking into account the high aromatic and low olefin content of TPO, the high $\mathrm{DBE}_{\text {avg }}$ values can be an indicator of the significant presence of condensed aromatic structures [53]. This hypothesis will be verified by the NMR results in the following section.

Table 2 also shows the H/C ratio found by means of APPI FT-ICR MS for both TPO and TPO[CaO]. The H/C gives a general idea about the molecular diversity of the sample (relative content of paraffins, aromatics, olefins, and naphthenes), as well as of the amount of heat released during combustion. For instance, aromatic rings have $\mathrm{H} / \mathrm{C}$ ratios close to unity, while paraffins have $\mathrm{H} / \mathrm{C}$ ratios closer to two [26]. This ratio also constrains the identity and population of the radical pool, which is a fundamental driver for the occurrence of chemical kinetic phenomena such as induction time, flame velocity, and diffusive extinction limit [81]. An H/C ratio of 1.46 in both samples reveals the presence of aliphatic and aromatic compounds, as reported previously in literature $[11,18,37,78]$. It is worth to note that the $\mathrm{H} / \mathrm{C}$ ratio shown in Table 2 is similar to the one calculated from elemental composition, which was reported in Table 1. This partially confirmed the reliability of our results at both the macroscopic (elemental analysis) and microscopic (molecular characterization by FT-ICR MS) views.

According to the chemical formula assigned to each resolved peak, species were grouped into different molecular classes, depending on their content of heteroatoms. Chemical formulas were classified into different compound classes, including HC (pure hydrocarbons), $\mathrm{S}_{1}$ (hydrocarbons with one sulfur atom), NS (hydrocarbons with one $\mathrm{N}$ atom and one $\mathrm{S}$ atom), and $\mathrm{S}_{2}$ (hydrocarbons with two $\mathrm{S}$ atoms), among others. Furthermore, positive APPI mode leads to protonated ions $[\mathrm{M}+\mathrm{H}]^{+}$along with the radical cations $\left[\mathrm{M}^{+} \cdot\right]$. In the present analysis $\mathrm{HC}[\mathrm{H}]$, $\mathrm{S}[\mathrm{H}], \mathrm{N}_{2}[\mathrm{H}], \mathrm{NO}[\mathrm{H}], \mathrm{O}[\mathrm{H}]$ and $\mathrm{O}_{2}[\mathrm{H}]$, were also recorded. However, to reduce the complexity and facilitate the comparison, molecular classes shown in Fig. 2 are the sum of both $\left[\mathrm{M}^{+} \cdot\right]$ and $[\mathrm{M}+\mathrm{H}]^{+}$. The relative abundance of each class was calculated as the total intensity of each compound class, divided by the total intensity of all of the assigned signals. 


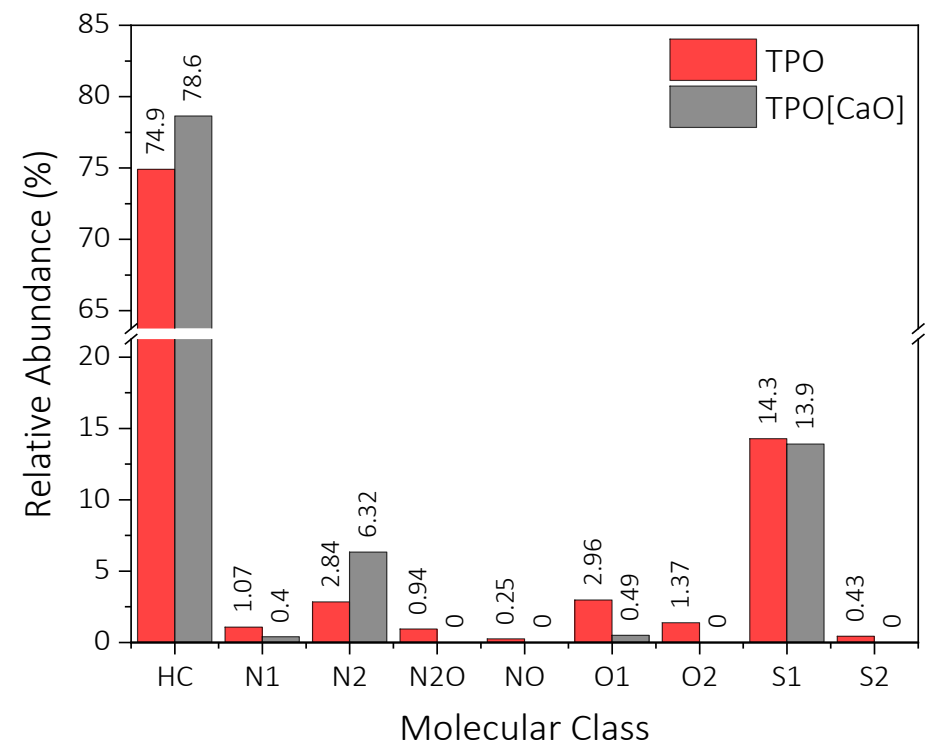

Fig. 2. Compound class distribution determined by APPI FT-ICR MS

The most abundant molecular classes observed in both samples were pure hydrocarbons (HC) and hydrocarbons containing one sulfur atom $\left(\mathrm{S}_{1}\right)$. The relative abundance of the $\mathrm{HC}$ compound class was higher in $\mathrm{TPO}[\mathrm{CaO}]$ than in TPO. The $\mathrm{S}_{1}$ class was slightly more abundant in TPO than in TPO[CaO]. Very low levels of hydrocarbon compounds containing two sulfur atoms $\left(\mathrm{S}_{2}\right)$ were detected in TPO, whereas none were detected in TPO[CaO]. The proportion of hydrocarbons with oxygen atoms $\left(\mathrm{O}_{1}\right)$ is slightly higher in TPO than in TPO[CaO]. The higher abundance of $\mathrm{HC}$ species, low quantities of $\mathrm{O}_{1}$, and absence of the $\mathrm{S}_{2}$ molecular class in $\mathrm{TPO}[\mathrm{CaO}]$ might be associated with the reactivity of $\mathrm{CaO}$ during the pyrolysis. Namely, it is likely that $\mathrm{CaO}$ either captures or transforms these heteroatoms contained in the volatile matter before they become part of the liquid hydrocarbon compounds, in turn, favoring a higher relative abundance of HC. For instance, the most abundant sulfur species contained in the volatile matter released from WT during pyrolysis are hydrogen sulfide $\left(\mathrm{H}_{2} \mathrm{~S}\right)$ and carbonyl sulfide (COS) [60]. In the presence of $\mathrm{CaO}$, these compounds react to form $\mathrm{CaS}$, which is found in the $\mathrm{rCB}$. Consequently, this phenomenon may result in a reduction of the sulfur concentration of TPO. Regarding $\mathrm{O}_{1}$, the possible decomposition of oxygenated compounds in the volatile matter via catalytic cracking $(\mathrm{CaO}$ as the catalyst) may lead to an increase in the concentration of $\mathrm{CO}$ [69]. In turn, $\mathrm{CO}$ might be involved in further reactions - water-gas shift reaction - along with $\mathrm{H}_{2} \mathrm{O}$ to produce $\mathrm{H}_{2}$ and $\mathrm{CO}_{2}$. Although $\mathrm{CO}_{2}$ is produced during the water-gas shift reaction, the presence of $\mathrm{CaO}$ in the system could react with it to produce $\mathrm{CaCO}_{3}$ (contained in the $\mathrm{rCB}$ ). 
These results agree with the information reported in Table 1, related to elemental analysis. The significant presence of $S_{1}$ compounds could mean that the core skeletal structures of the molecules might be thiophenic or thiolic in nature. Understanding the nature of sulfur atoms in these fuels is fundamental in choosing proper desulfurization techniques, as will be discussed later [82]. Furthermore, there is a great interest for studying the structure of the PASH present in fuels, because some of them can have carcinogenic and mutagenic effects on humans. Therefore, knowledge of the structure of the sulfur-containing compounds allows for a more precise assessment of the health hazards associated with new fuels such as TPO [78].

Given that $\mathrm{HC}$ and $\mathrm{S}_{1}$ are the most abundant molecular classes, both were divided into subfamilies with respect to their DBE number. The utilization of DBE values allows for the distinction of molecular structures according to their unsaturation degree (presence of both double bonds and rings in the molecule) [79]. For instance, DBE numbers between 10 and 12 could be related to tri-aromatics and naphtheno-aromatics $(\operatorname{Tr} A)$, while values between 13 and 14 are related to tetra-aromatics and to tetra-aromatics with naphthenic rings (TeA). Finally, DBE values higher than 16 could be associated with penta and higher aromatics, including naphthenic rings $(\mathrm{PA}+)$ [41]. Table 3 provides the minimum and maximum number of carbon atoms for each subfamily.

Table 3. Range of the DBE number of carbon atoms per subfamily of pure hydrocarbons (HC) class

\begin{tabular}{llllll}
\hline \multirow{2}{*}{ DBE } & \multirow{2}{*}{ Compound family } & TPO & \multicolumn{3}{c}{ TPO[CaO] } \\
\cline { 3 - 6 } & Min & Max & Min & Max \\
\hline 0 & N & - & - & - & - \\
1 & DN & - & - & - & - \\
$2-3$ & MA & 12 & 35 & - & - \\
$4-6$ & DA+ & 12 & 45 & 14 & 39 \\
$7-9$ & 13 & 50 & 16 & 46 \\
$10-12$ & TrA+ & 17 & 56 & 18 & 51 \\
$13-14$ & TeA+ & 20 & 56 & 21 & 53 \\
$16+$ & PA+ & 22 & 56 & 22 & 53 \\
\hline P: Normal Paraffins and Isoparaffins; N: Naphthenes; DN: Dinaphthenes; MA: Monoaromatics, \\
DA+: Diaromatics and Naphtheno-Aromatics; TrA+: Triaromatics and Naphtheno-Aromatics; \\
TeA+: Tetraaromatics and tetraaromatics with Naphthenic Rings; PA+: Pentaaromatics and higher, \\
including Naphthenic Rings.
\end{tabular}

The distribution of compounds contained in the HC molecular class as a function of DBE and carbon number are illustrated in Fig. 3. The bubble size denotes the magnitude (relative abundance) of the recorded mass peaks. As observed, the most abundant compounds in both samples are in the carbon number range between 20 and 45 , and DBE numbers between 5 and 20. A wider carbon range is noticed in TPO $\left(\mathrm{C}_{15}-\mathrm{C}_{58}\right)$ than in TPO[CaO] $\left(\mathrm{C}_{15^{-}}\right.$ $\mathrm{C}_{53}$ ), which is in agreement with the $\mathrm{MW}_{\text {avg }}$ and final distillation boiling points discussed above. The high final 
boiling point found for both samples could be explained by the presence of heavy compounds with large DBE values (>20), likely linked to condensed aromatic structures [83]
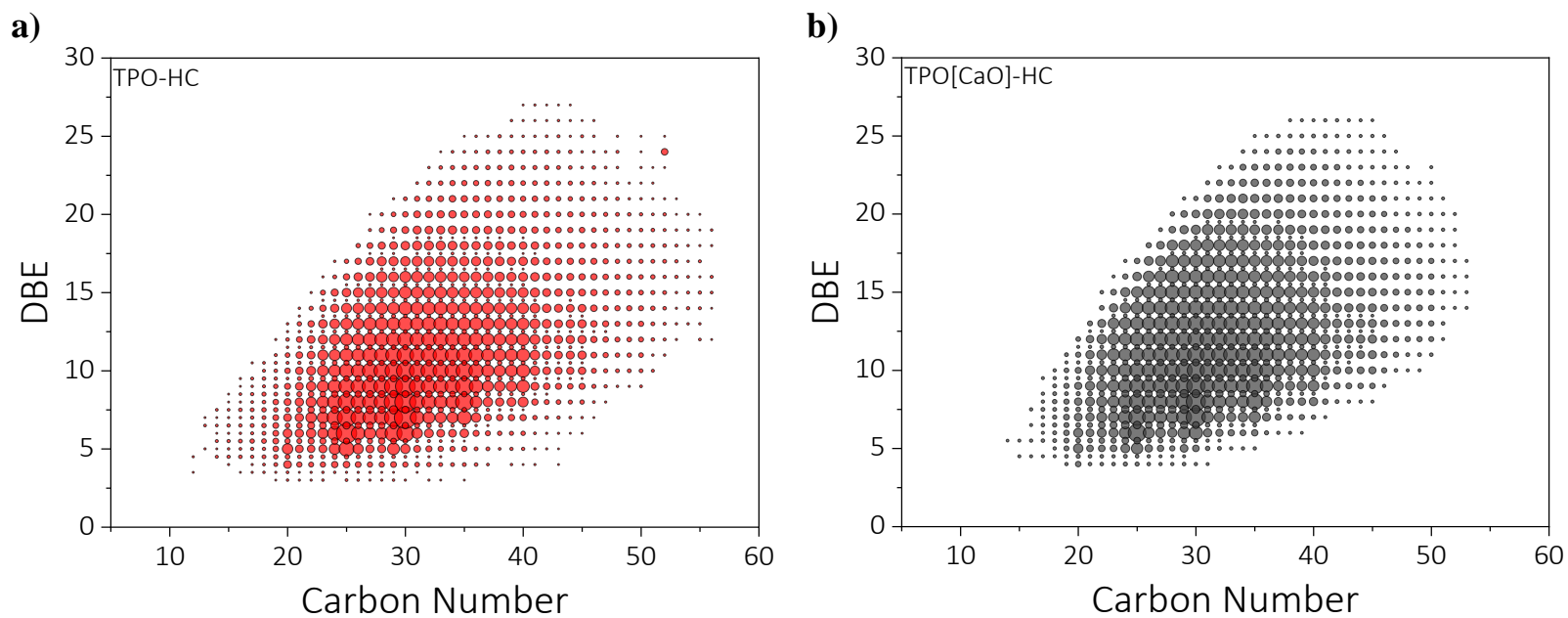

Fig. 3. Abundance of pure hydrocarbon (HC) compounds: a) TPO; b) TPO [CaO]

Similarly, for the $S_{1}$ molecular class, Table 4 reports the carbon number distribution for each subfamily. Subfamilies are also classified according to the DBE number. In this regard, S subfamilies are divided into monosulfur containing species like sulfides (SD) and PASH structures such as thiophene (DBE: 3 ), benzothiophenes (DBE: 6), dibenzothiophene (DBE: 9), benzonaphthothiophene (DBE: 12) and their related naphthenic derivatives (DBE number ranges 4 - 5, 7 - 8, 10 - 11, and 13 - 15). Herein, the carbon range number for TPO and TPO $[\mathrm{CaO}]$ is between 13 and 20; and, 19 and 45, respectively.

Table 4. Range of the DBE number of carbon atoms per subfamily of S molecular class

\begin{tabular}{llllll}
\hline \multirow{2}{*}{ DBE } & \multirow{2}{*}{ Compound family } & \multicolumn{2}{c}{ TPO } & \multicolumn{3}{c}{ TPO[CaO] } \\
\cline { 3 - 6 } $0-2$ & SD & min & $\max$ & $\min$ & $\max$ \\
\hline $3-5$ & Th & - & - & - & - \\
$6-8$ & BT & 13 & 35 & 19 & 30 \\
$9-11$ & DBT & 18 & 45 & 19 & 41 \\
$12+$ & BNT & 19 & 50 & 19 & 45 \\
\hline SD: Sulfide; Th: Thiophene; BT: Benzothiophenes; DBT: Dibenzothiophene; \\
BNT: Benzonaphthothiophene
\end{tabular}

Fig. 4 shows the distribution of compounds contained in the $S_{1}$ molecular class as a function of DBE and carbon number. As observed, compounds with carbon numbers between 25 and 35 and DBE numbers between 5 and 10 are the most abundant in this molecular class. PASH in TPO and TPO[CaO] show the presence of 
molecules with carbon numbers up to 50 and 45, respectively; which can be associated with long or multiple short alkyl chains connected to the aromatic rings [53].
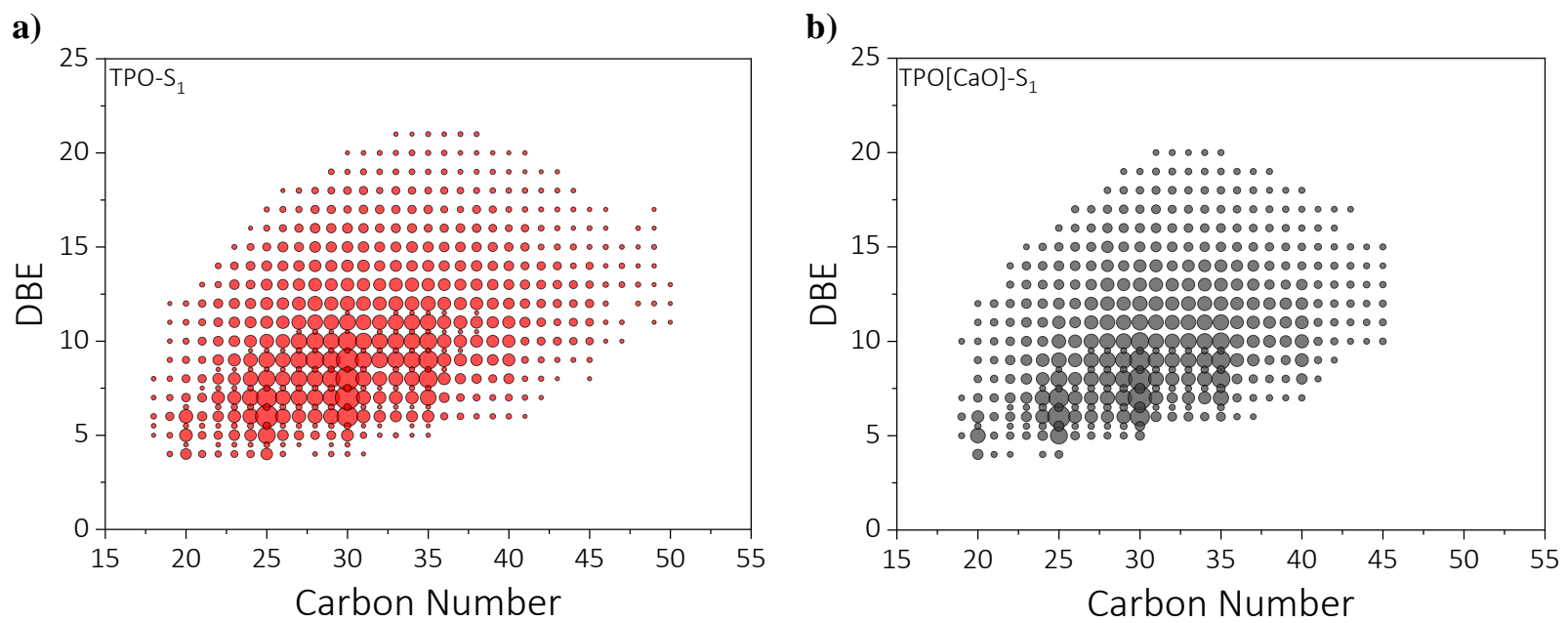

Fig. 4. Abundance of Mono-sulfur $\left(\mathrm{S}_{1}\right)$ compounds: a) TPO; b) TPO [CaO]

The $\mathrm{HC}$ and $\mathrm{S}_{1}$ compound distributions according to the subfamilies previously described, and their cumulative abundances are plotted in Figs. 5a and 5b, respectively. As observed in Fig. 5a, $61 \%$ and $71 \%$ of the HC compounds in TPO and TPO[CaO] are found in the form of $\mathrm{TrA}$, TeA and PAt, respectively. The HC distribution does not show any fully saturated hydrocarbon species (DBE numbers between 0 and 3), which could be due to their absence, or to the inability of alkanes to form stabilized ions using APPI ionization [84].

a)

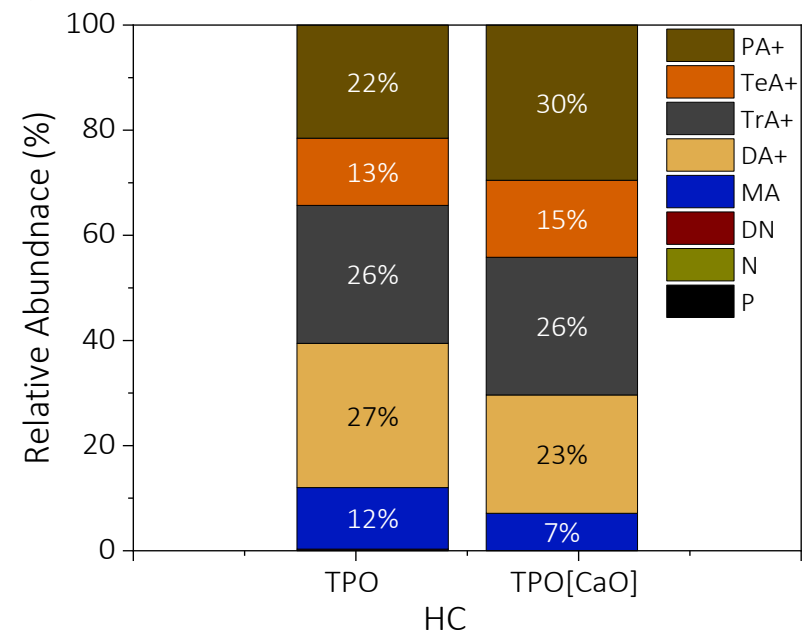

b)

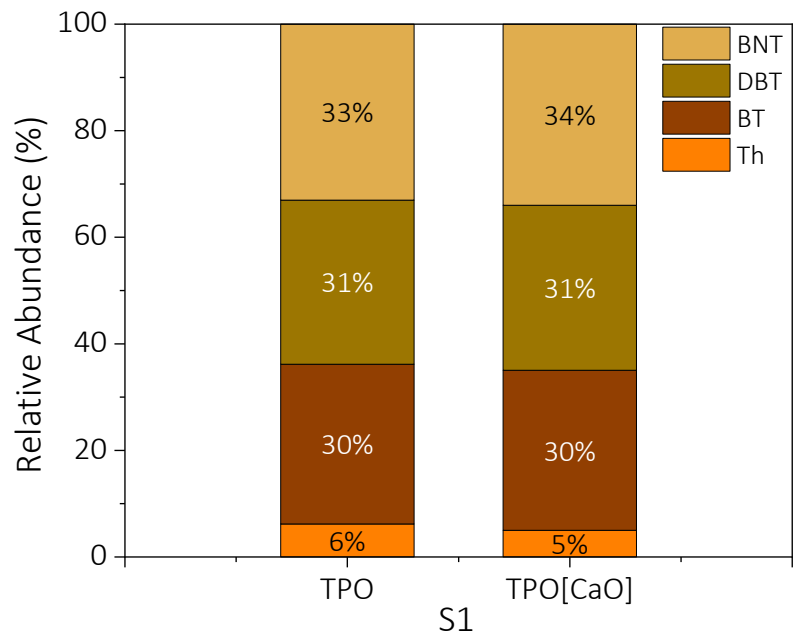

Fig. 5. Compound subfamilies according to their DBE number and cumulative abundance

On the other hand, Fig. 5b shows that more than $60 \%$ of the sulfur-containing compounds are in the form of dibenzothiophene (DBT) and benzonaphthothiophene (BNT). Similar results were found by Williams and 
Bottrill [78], who reported that the PASH present in TPO consist mainly of DBT, alkylated DBT, and naphthothiophenes, along with their methyl derivatives. However, due to the limitations of the analytical techniques used in that work (GC-MS), a large portion of the PASH, particularly high molecular weight compounds, could not be identified. It has been reported that highly condensed aromatic compounds of high molecular weight are formed in the pyrolysis of WT, and heteroatoms are incorporated. These compounds could be formed during pyrolysis or after vapor condensation.

As discussed before, a proper understanding of the molecular characteristics of the compounds present in TPO helps to select and optimize upgrading strategies (e.g. desulfurization steps). Different sulfur-containing compounds behave in a different manner when exposed to diverse desulfurization processes (i.e. oxidative desulfurization, hydrodesulfurization, extractive desulfurization, etc.) [35]. For example, regarding the removal of heterocyclic sulfur compounds such as DBT, as well as its derivatives (4,6-dimethyldibenzothiophene), hydrodesulfurization is not effective [56,85]. Previous hydrodesulfurization studies of diesel fuel have revealed that alkyl dibenzothiophene remains at a level of $0.1 \mathrm{wt} \%$, given that these kinds of compounds have low reactivity during hydrodesulfurization [82]. The major cause of low reactivity has been attributed to the steric hindrance presented by bulky sulfur containing aromatics. Alternatively, techniques such as oxidative desulfurization present higher reactivity when sulfur compounds are in the form of BT and DBT [86]. An attractive aspect of this technique is the higher reactivity of aromatic sulfur species with three or more aromatic rings, which is associated with the increase in electron density when sulfur atoms are set in a larger aromatic scheme. This electron density is also improved with the presence of alkyl groups in the aromatic rings. All these facts favor the electrophilic attack by oxidants [87]. In this regard, and according to the APPI FT-ICR results, oxidative desulfurization could be a promising pathway for TPO upgrading.

The high abundance of $\mathrm{PAH}$ in TPO and TPO$[\mathrm{CaO}]$ is due to the aromatic nature of rubber (one aromatic ring is present in the styrene butadiene rubber monomer) and the cyclisation of olefin structures, followed by dehydration and Diels-Alder reactions [11]. Such aromatization reactions are enhanced at high pyrolysis temperatures, as well as prolong residence times of the volatiles inside the reactor. Likewise, previous studies have shown the formation of aromatics in TPO from the thermal decomposition of limonene (one of the major 
components of TPO) [28]. Ding et al. [88] reported that such a process can occur in a temperature range between $400^{\circ} \mathrm{C}$ and $700^{\circ} \mathrm{C}$. Herein, limonene isomerizes to form 4-isopropylidene-1-methylcyclohexene at temperatures below $500^{\circ} \mathrm{C}$. At $600^{\circ} \mathrm{C}$, this compound then undergoes carbon-carbon bond cleavage, which is followed by an intramolecular hydrogen transfer to form an alkatriene. Consequently, intramolecular diene synthesis, followed by dehydration, leads to the formation of aromatics such as xylene and toluene. When the temperature reaches $700^{\circ} \mathrm{C}$, aromatization reactions can initiate further $\mathrm{PAH}$ formation.

Similarly, the formation of PASH in TPO during pyrolysis has been attributed to the combinations of available olefins and free sulfur atoms, the combination of sulfur-containing compounds with olefins via the Diels-Alder reactions, and the direct cracking of WT molecules where sulfur atoms resided. A complete description of the reaction mechanisms for the formation of PASH during the pyrolysis of WT have been presented in a previous work conducted by Dung et al. [67].

Table 5 shows different molecular parameters found in TPO and TPO $[\mathrm{CaO}]$. Noteworthy facts are the high $\mathrm{MW}_{\text {avg }}$ of $\mathrm{S}_{1}$ (higher than $440 \mathrm{~g} / \mathrm{mol}$ ) and their high DBE number ( 10). HC species exhibit a $\mathrm{MW}_{\text {avg }}$ of 419.97 and $428.82 \mathrm{~g} / \mathrm{mol}$, while the average DBE numbers are around 10.20 and 12.38 for TPO and TPO[CaO], respectively. Considering that the $S_{1}$ molecular class exhibits a high average molecular weight, another path to remove sulfur-containing compounds contained in TPO and TPO $[\mathrm{CaO}]$ could be fractional distillation. Even though distillation will not remove the sulfur atoms from the fuel, sulfur containing compounds can be concentrated in the leftover heavy fraction.

Table 5. Molecular parameters of $\mathrm{HC}$ and $\mathrm{S}_{1}$ compound classes

\begin{tabular}{lllll}
\hline \multirow{2}{*}{ Parameter } & TPO & \multicolumn{3}{c}{ TPO[CaO] } \\
\cline { 2 - 5 } & HC & $\mathbf{S}_{\mathbf{1}}$ & HC & $\mathbf{S}_{\mathbf{1}}$ \\
\hline MW $_{\text {avg }}(\mathrm{g} / \mathrm{mol})$ & 419.97 & 447.83 & 428.82 & 444.56 \\
Average DBE Number & 10.20 & 10.28 & 12.38 & 10.33 \\
Average H/C ratio & 1.35 & 1.39 & 1.29 & 1.39 \\
\hline
\end{tabular}

In addition, Fig. 6 illustrates the characteristics of other molecular classes $\left(\mathrm{O}_{1}, \mathrm{~N}_{1}\right.$ and $\left.\mathrm{N}_{2}\right)$ present in TPO and $\mathrm{TPO}[\mathrm{CaO}]$ based on their carbon and DBE numbers. Similar distributions are found in the $\mathrm{N}_{2}$ molecular class for both samples: compounds with carbon and DBE numbers in the range of 15-40 and 10-20, respectively. In contrast, significant differences are observed in $\mathrm{O}_{1}$ and $\mathrm{N}_{1}$ molecular classes between TPO and TPO[CaO]. A 
significant reduction of the identified compounds belonging to these molecular classes is noticed in TPO[CaO].

These results are aligned with the information obtained from the elemental analysis, reported in Table $\mathbf{1 .}$

a)

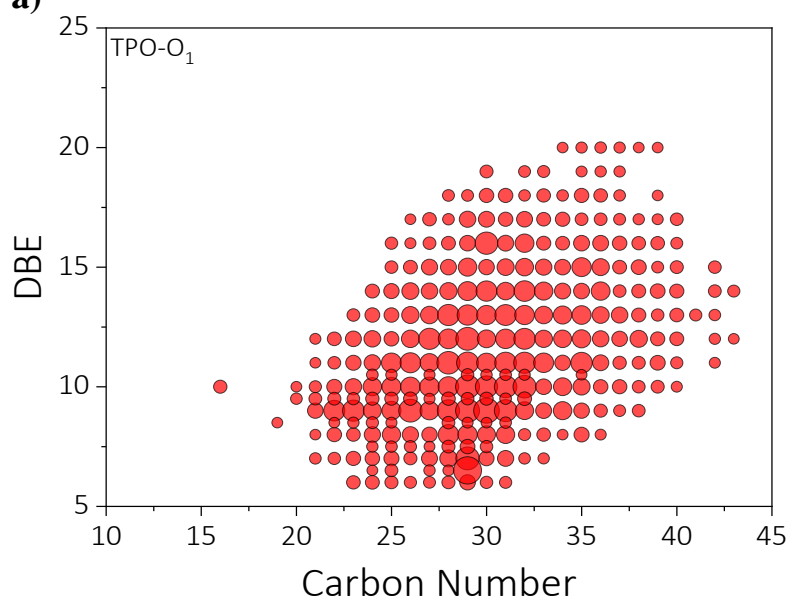

c)

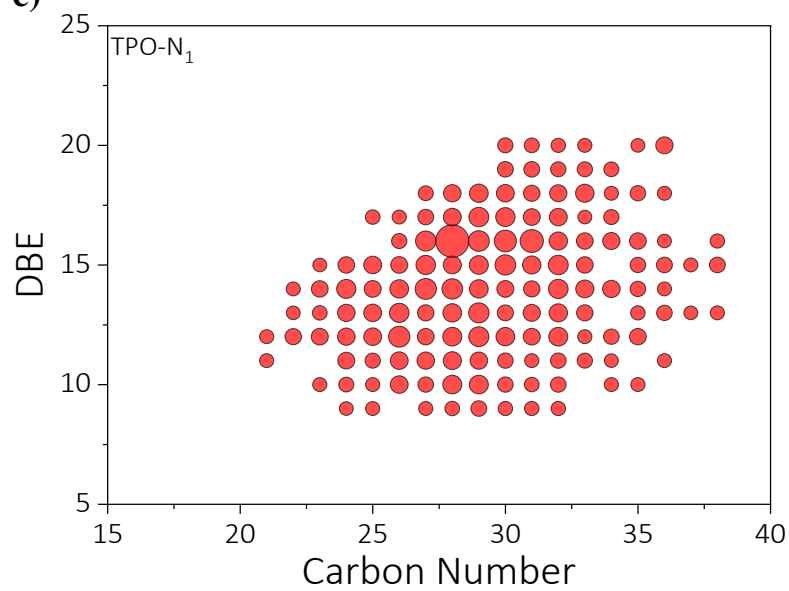

e)

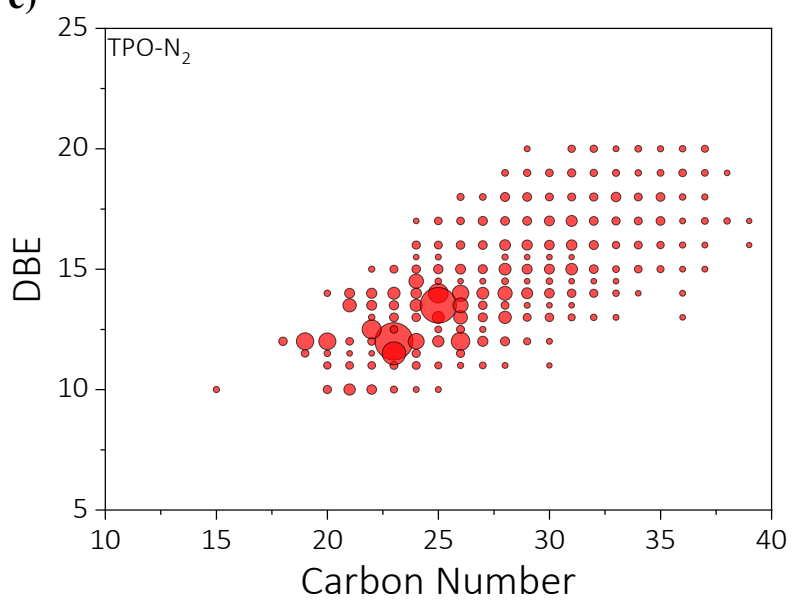

b)

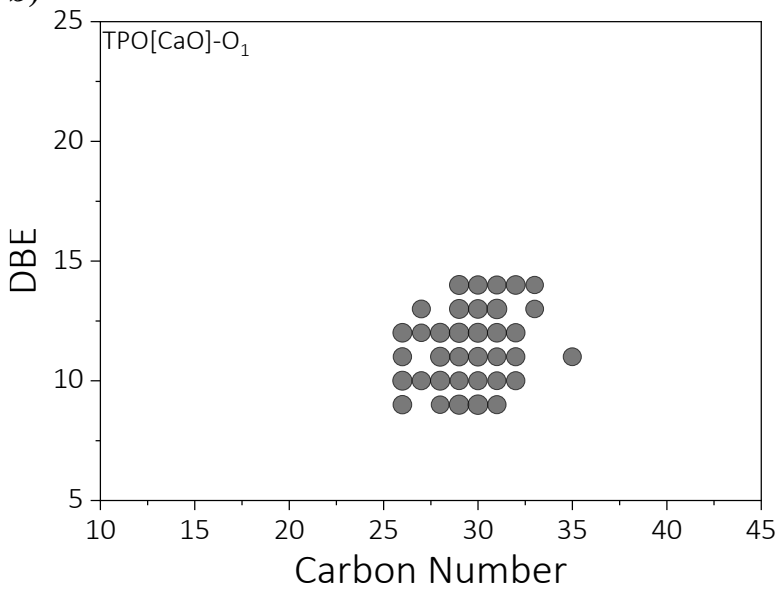

d)

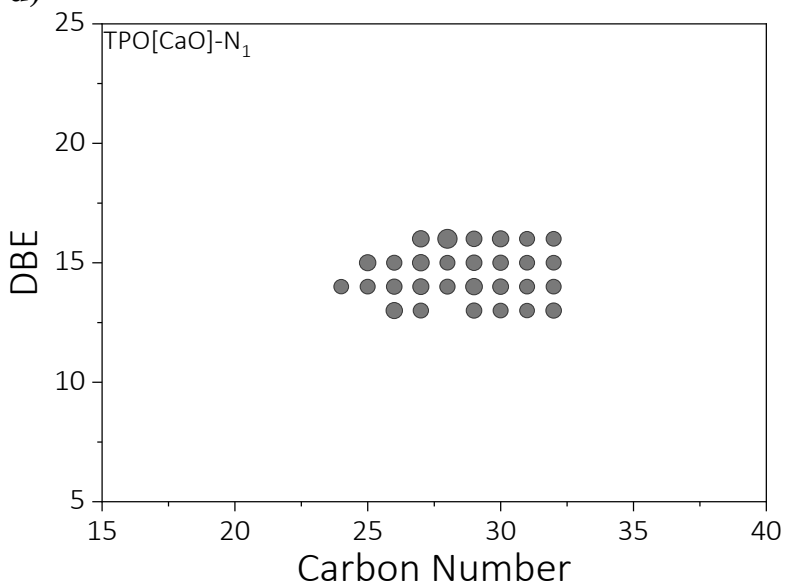

f)

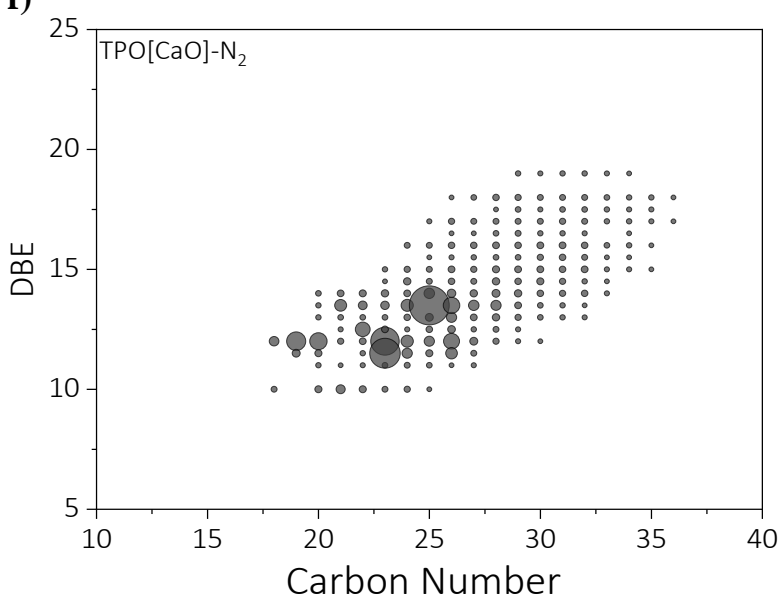

Fig. 6. Molecular class distribution of $\mathrm{O}_{1}, \mathrm{~N}_{1}$ and $\mathrm{N}_{2}$ compounds 


\section{$3.3{ }^{1} \mathrm{H}$ and ${ }^{13} \mathrm{C}$ NMR}

Combining the data from ${ }^{1} \mathrm{H}$ NMR, ${ }^{13} \mathrm{C}$ NMR spectra, elemental analysis (Table 1), and $\mathrm{MW}_{\text {avg }}$ (Table 2), it is possible to characterize a complex fuel in terms of its AMPs. The average molecular formula of TPO and $\mathrm{TPO}[\mathrm{CaO}]$ obtained by means of Equation 4 are $\mathrm{C}_{31.09} \mathrm{H}_{45.05} \mathrm{~N}_{0.41} \mathrm{~S}_{0.09} \mathrm{O}_{0.21}$ and $\mathrm{C}_{31.00} \mathrm{H}_{45.16} \mathrm{~N}_{0.37} \mathrm{~S}_{0.07} \mathrm{O}_{0.10}$, respectively. Tables 6 and Table 7 present the characteristic ${ }^{1} \mathrm{H}$ and ${ }^{13} \mathrm{C}$ NMR chemical shift used to identify and quantify several nuclei, as well as the related AMPs calculated using Equation 3. The ${ }^{1} \mathrm{H}$ chemical shift assignments were taken from Abdul Jameel et al. [26] and the ${ }^{13} \mathrm{C}$ NMR assignments were obtained from Poveda and Molina [31]. The formulae and terminology used to denote and calculate the AMPs follows the methodology of Poveda and Molina [31] and from Abdul Jameel et al. [49].

Table 6. ${ }^{1} \mathrm{H}$ NMR chemical shift assignments

\begin{tabular}{|c|c|c|c|c|c|c|}
\hline \multirow[b]{2}{*}{ Symbol } & \multirow[b]{2}{*}{ Hydrogen type } & \multirow{2}{*}{$\begin{array}{l}\text { Chemical } \\
\text { shift }\end{array}$} & \multicolumn{2}{|l|}{ TPO } & \multicolumn{2}{|l|}{ TPO $[\mathrm{CaO}]$} \\
\hline & & & Mole (\%) & $\begin{array}{l}\text { Number } \\
\text { of atoms }\end{array}$ & Mole (\%) & $\begin{array}{l}\text { Number } \\
\text { of atoms }\end{array}$ \\
\hline $\mathrm{H}_{\text {Arom }}$ & Aromatics & $6.42-8.99$ & 9.21 & 4.15 & 10.96 & 4.95 \\
\hline Hole & Olefinic $\mathrm{CH}-\mathrm{CH}_{2}$ groups & $4.50-6.42$ & 7.55 & 3.40 & 8.04 & 3.63 \\
\hline $\mathrm{H}_{\mathrm{CH} \alpha}$ & $\mathrm{CH}$ group $\alpha$ to aromatic ring & $2.88-3.40$ & 0.72 & 0.32 & 0.85 & 0.38 \\
\hline $\mathrm{H}_{\mathrm{CH} 2 \alpha}$ & $\mathrm{CH}_{2}$ group $\alpha$ to aromatic ring & $2.64-2.88$ & 1.03 & 0.46 & 1.45 & 0.65 \\
\hline $\mathrm{H}_{\mathrm{CH} 3 \alpha}$ & $\mathrm{CH}_{3}$ group $\alpha$ to aromatic ring & $2.04-2.64$ & 12.49 & 5.63 & 13.8 & 6.23 \\
\hline $\mathrm{H}_{\mathrm{Naph}}$ & Naphthenic $\mathrm{CH}-\mathrm{CH}_{2}$ groups & $1.57-1.96$ & 14.8 & 6.67 & 16.45 & 7.43 \\
\hline HPar-CH & Paraffinic $\mathrm{CH}$ groups & $1.39-1.57$ & 3.52 & 1.59 & 2.67 & 1.21 \\
\hline HPar-CH2 & Paraffinic $\mathrm{CH}_{2}$ groups & $0.94-1.39$ & 22.83 & 10.28 & 19.96 & 9.01 \\
\hline HPar-CH3 & Paraffinic $\mathrm{CH}_{3}$ groups & $0.25-0.94$ & 27.85 & 12.55 & 25.82 & 11.66 \\
\hline Total & & & 100.00 & 40.05 & 100.00 & 45.16 \\
\hline
\end{tabular}

Table 7. ${ }^{13} \mathrm{C}$ NMR chemical shift assignments

\begin{tabular}{|c|c|c|c|c|c|c|}
\hline \multirow[b]{2}{*}{ Symbol } & \multirow[b]{2}{*}{ Carbon type } & \multirow[b]{2}{*}{$\begin{array}{l}\text { Chemical } \\
\text { shift }\end{array}$} & \multicolumn{2}{|l|}{ TPO } & \multicolumn{2}{|c|}{ TPO $[\mathrm{CaO}]$} \\
\hline & & & Mole (\%) & $\begin{array}{l}\text { Number } \\
\text { of atoms }\end{array}$ & Mole (\%) & $\begin{array}{l}\text { Number } \\
\text { of atoms }\end{array}$ \\
\hline $\mathrm{C}_{\mathrm{Ar}}$ & Aromatic quaternary $\mathrm{C}$ & $140.5-160.0$ & 3.81 & 1.18 & 4.25 & 1.32 \\
\hline $\mathrm{C}_{\text {Ara-S }}$ & Aromatic quaternary $\mathrm{C} \alpha$ to $\mathrm{S}$ atom & $137.0-140.5$ & 2.04 & 0.63 & 1.82 & 0.56 \\
\hline $\mathrm{C}_{\mathrm{Ar} \alpha-\mathrm{CH} 3}$ & Aromatic $\mathrm{C} \alpha$ to position $\mathrm{CH}_{3}$ group & $131.7-137.0$ & 6.8 & 2.11 & 7.08 & 2.19 \\
\hline $\mathrm{C}_{\mathrm{AA}}$ & Aromatic $\mathrm{C}$ bridging 2 aromatic rings & $129.2-131.7$ & 6.95 & 2.16 & 7.1 & 2.20 \\
\hline $\mathrm{C}_{\mathrm{AAA}}$ & Aromatic $\mathrm{C}$ bridging 3 rings & & 1.92 & 0.60 & 2.04 & 0.63 \\
\hline Cole & Olefinic $\mathrm{CH}-\mathrm{CH}_{2}$ & $85.0-129.2$ & 5.51 & 1.71 & 6.29 & 1.95 \\
\hline $\mathrm{C}_{\mathrm{Ar}-\mathrm{H}}$ & Aromatic protonated $\mathrm{C}$ & & 14.5 & 4.51 & 17.23 & 5.34 \\
\hline $\mathrm{C}_{\mathrm{Par}-\mathrm{C}}$ & Paraffinic quaternary $\mathrm{C}$ & $50.0-60.0$ & 0.4 & 0.12 & 0 & 0.00 \\
\hline $\mathrm{C}_{\mathrm{Naph}}$ & Naphthenic $\mathrm{CH}-\mathrm{CH}_{2}$ & $40.5-50.0$ & 10.2 & 3.17 & 11.85 & 3.67 \\
\hline $\mathrm{C}_{\mathrm{Par}-\mathrm{CH}}$ & Paraffinic $\mathrm{CH}$ & $35.0-40.5$ & 2.67 & 0.83 & 2.48 & 0.77 \\
\hline $\mathrm{CPar}-\mathrm{CH} 2$ & Paraffinic $\mathrm{CH}_{2}$ & $21.5-35.0$ & 23.74 & 7.38 & 20.38 & 6.32 \\
\hline CPar-CH3 $\alpha-\mathrm{Ar}$ & Paraffinic $\mathrm{CH}_{3} \alpha$ to aromatic ring & $18.5-21.5$ & 7.05 & 2.19 & 6.76 & 2.10 \\
\hline $\mathrm{C}_{\mathrm{Par}-\mathrm{CH} 3}$ & Paraffinic $\mathrm{CH}_{3}$ & $3.0-18.5$ & 14.41 & 4.48 & 12.72 & 3.94 \\
\hline Total & & & 100.00 & 31.09 & 100.00 & 31.00 \\
\hline
\end{tabular}

As mentioned in the section of materials and methods, different nuclei exhibit different shifts. Accordingly, the splitting pattern and position of these shifts are indicative of the underlying molecular structure. Thus, it is 
possible to determine the relative amount of each molecular functional group and atomic arrangement, such as aromatic carbons, olefinic carbon, aromatic hydrogen, naphthenic hydrogen, etc. Fig. 7 shows the distribution of hydrogen (Fig. 7a) and carbon (Fig. 7b) types in TPO and TPO $[\mathrm{CaO}]$, according to different hydrocarbon subfamilies. NMR data reveals that there is a significant presence of hydrogen and carbon atoms in paraffinic structures for both samples. In contrast to TPO, TPO $[\mathrm{CaO}]$ exhibits a higher content of hydrogen and carbon atoms in aromatic, naphthenic, and olefinic structures, while lower hydrogen and carbon atoms in paraffinic ones. This trend can be associated with the participation of $\mathrm{CaO}$ in diverse chemical reactions during tire pyrolysis.
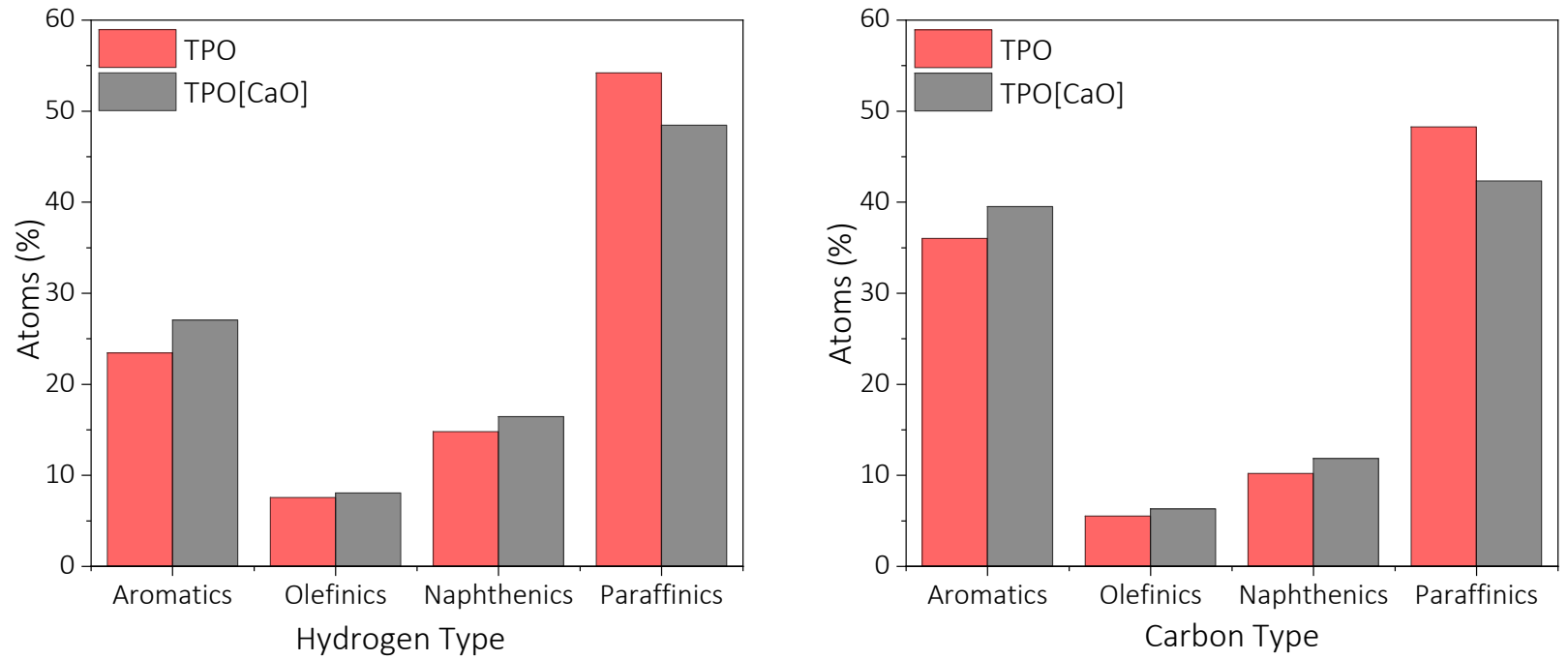

Fig. 7. Atomic distribution by hydrocarbon families

First, the polarity of the active sites of $\mathrm{CaO}$ may affect the stability of the $\pi$-electron cloud in $\mathrm{PAH}$ [69]. The $\mathrm{O}^{2-}$ ions that form the active sites on the $\mathrm{CaO}$ particles have spatially diffused electron clouds that induce an instability of the electron clouds of PAH present in the volatile matter, destabilizing their aromatic rings. This phenomenon may lead to ring splitting and, eventually, more protonated aromatic rings, naphthenes, and/or olefins can be formed [71,89]. In addition, the $\mathrm{O}^{2-}$ ions may also abstract $\mathrm{H}^{+}$ions from long paraffinic chains. In turn, smaller hydrocarbon chains could be generated. In addition, in the presence of $\mathrm{CaO}$, coupled with the high temperature of pyrolysis, these new chains may reorganize to form olefins, cycloparaffins (naphthenes), or even aromatics [90]. 
Fig. 8 shows the distribution of hydrogen atoms along with their cumulative frequency for TPO and TPO[CaO]. Hydrogen atoms in methylene $\left(\mathrm{CH}_{2}\right)$, methyl $\left(\mathrm{CH}_{3}\right)$, and naphthenic groups, as well as hydrogen atoms in aromatic rings make up more than $80 \%$ of both samples. This can be associated with the presence of multiple shorter paraffinic chains instead of longer ones attached to aromatic structures [49].

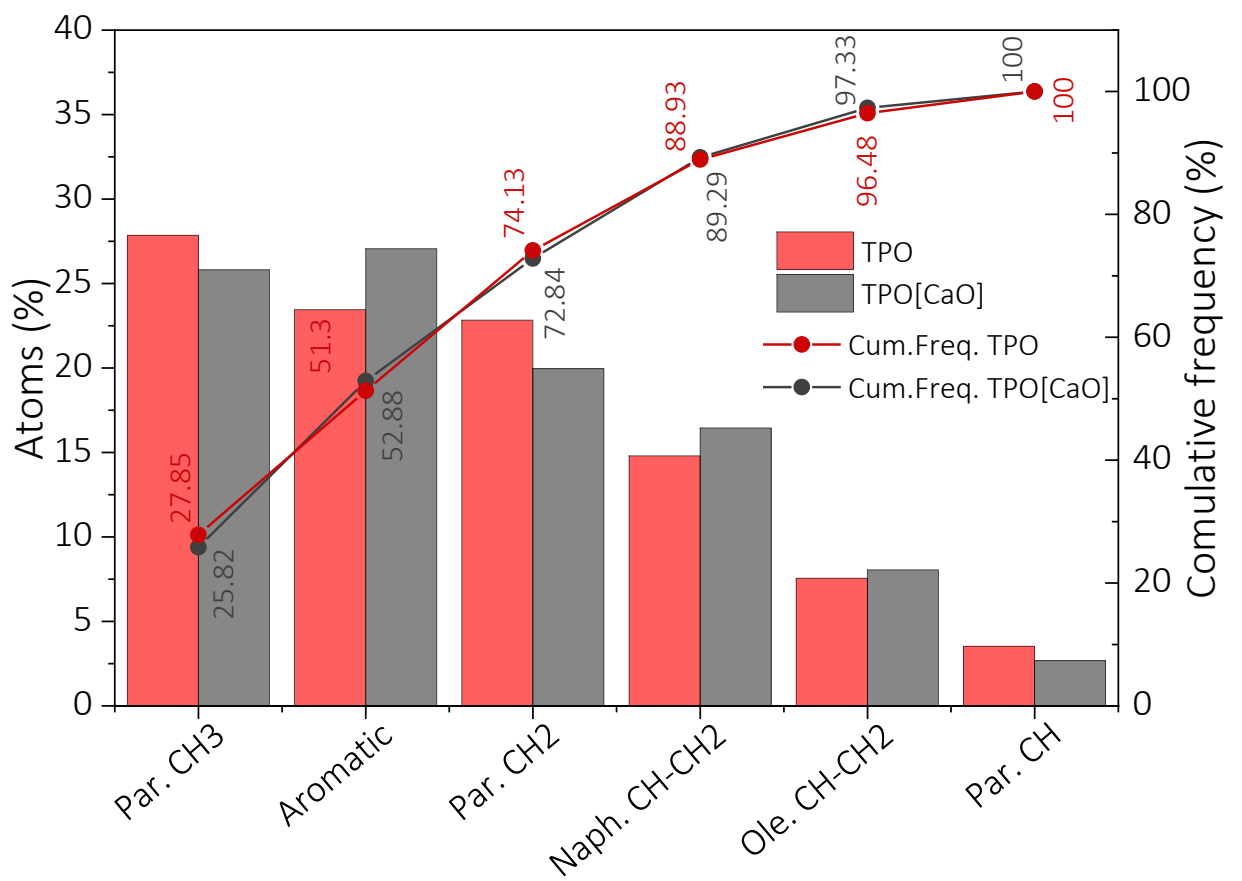

Fig. 8. Hydrogen type distribution

On the other hand, carbon atoms in paraffins such as methylene $\left(\mathrm{CH}_{2}\right)$ and methyl $\left(\mathrm{CH}_{3}\right)$ groups, and protonated carbon atoms in aromatic structures, make up around $50 \%$ of both TPO and TPO $[\mathrm{CaO}]$, as shown in Fig. 9. The number of carbon atoms in aromatic structures is higher than the number of hydrogen atoms, which means that some carbon atoms are non-protonated [53]. This suggests that the carbon atoms in aromatic compounds are either present in condensed structures or connected to paraffinic side chains, as aforementioned. 


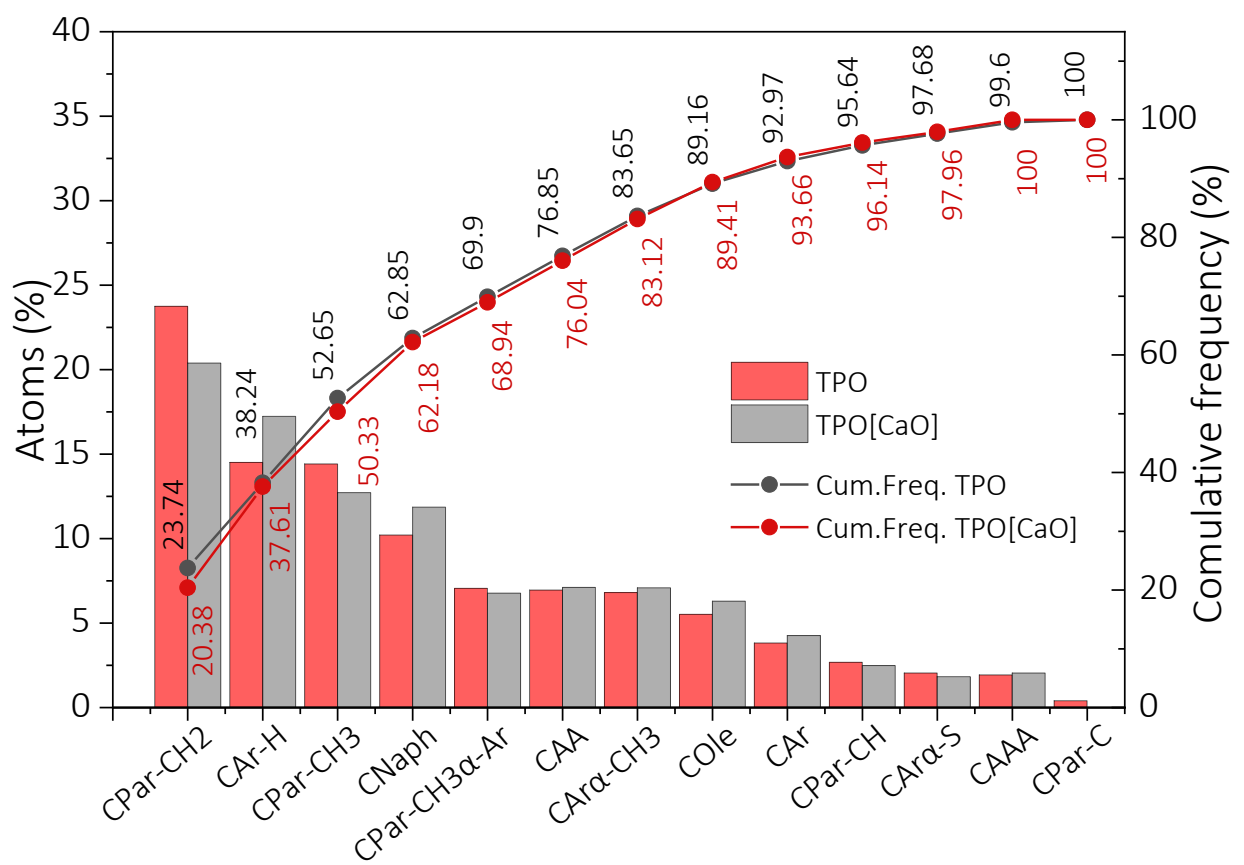

Fig. 9. Carbon type distribution

Based on the hydrogen and carbon type distributions obtained from ${ }^{1} \mathrm{H}$ and ${ }^{13} \mathrm{C}$ NMR reported in Table 6 and

Table 7, the derived AMPs for both samples were calculated. Derived AMPs are a group of dimensionless quantities obtained by re-arranging the AMPs, which provide an overall understanding of the structure of complex mixtures. The formulae used to calculate these derived AMPs were taken from Poveda and Molina [31]. The derived AMPs calculated for TPO and TPO $[\mathrm{CaO}]$ are listed in Table 8. Herein, $f_{a}$ is related to the aromatic content, and it is defined as the ratio of carbon atoms in aromatic compounds to total carbon atoms in the sample. In this regard, TPO $[\mathrm{CaO}]$ was found to be $11 \%$ more aromatic $\left(f_{a}=0.40\right)$ than $\mathrm{TPO}\left(f_{a}=0.36\right) . \mathrm{C} / \mathrm{H}$ is the ratio of the number of carbon atoms to the number of hydrogen atoms in the fuel. Values of $0.68(\mathrm{H} / \mathrm{C}=1.47)$ for this parameter confirms the presence of both paraffinic and aromatic structures in the fuels.

Table 8. Derived AMPs for TPO and TPO[CaO]

\begin{tabular}{llcc}
\hline Derived AMP & Description & TPO & TPO[CaO] \\
\hline Aromaticity & Ratio of the number of aromatic C atoms to total number of C atoms in the sample & 0.36 & 0.40 \\
factor $\left(f_{a}\right)$ & Ratio of number of C atoms to H atoms in the paraffinic content of the sample & 0.61 & 0.60 \\
$(\mathrm{C} / \mathrm{H})$ Paraffinic & Ratio of number of C atoms to H atoms in the aromatic content of the sample & 2.48 & 2.70 \\
$(\mathrm{C} / \mathrm{H})_{\text {Aromatic }}$ & Ratio of number of C atoms to H atoms in the sample & 0.69 & 0.69 \\
$\mathrm{C} / \mathrm{H}$ & Average number of C atoms in paraffinic chains connected with aromatic rings & 5.15 & 2.78 \\
$\mathrm{n}_{\mathrm{acl}}$ & Total number of naphthenic rings in an average molecule & 1.22 & 1.41 \\
$\mathrm{R}_{\mathrm{N}}$ & Total number of aromatic rings in an average molecule & 3.46 & 7.00 \\
$\mathrm{R}_{\mathrm{A}}$ & Total number of rings in an average molecule & 4.69 & 4.88 \\
$\mathrm{R}_{\mathrm{T}}$ & Ratio of total number of aromatic C in poly-condensed structures to number of & 0.25 & 0.23 \\
$\phi$ & aromatic C atoms & &
\end{tabular}


Likewise, a value of $(\mathrm{C} / \mathrm{H})$ aromatic of around 3 indicates that 3 out of 6 aromatic carbons are non-protonated. Therefore, the aromatic rings are present in condensed structures (cata- or peri-condensed) or have multiple side chains connected to them. This confirms the hypothesis previously established according to the results of APPI FT-ICR MS. The average number of $\mathrm{C}$ atoms in paraffinic chains connected with aromatic rings $\left(\mathrm{n}_{\mathrm{acl}}\right)$ exhibits a significant difference between TPO $\left(\mathrm{n}_{\mathrm{acl}}=5.57\right)$ and TPO[CaO] $\left(\mathrm{n}_{\mathrm{acl}}=2.78\right)$. The smaller chain length of $\mathrm{TPO}[\mathrm{CaO}]$ is explained by the possible cracking effect of $\mathrm{CaO}$ on long hydrocarbon chains. The phenomenon can also be noticed by the higher $\mathrm{R}_{\mathrm{N}}$ and $\mathrm{R}_{\mathrm{A}}$ of $\mathrm{TPO}[\mathrm{CaO}]$, in contrast to TPO. In the case of $(\mathrm{C} / \mathrm{H})_{\text {Paraffinic }}$, a value of $\sim 0.6$ in $\mathrm{TPO}[\mathrm{CaO}]$ and implies that most paraffinic structures are straight-chained, with a slight presence of paraffinic structures with branched chains.

The condensation index $(\phi)$ helps to establish the relationship between the total number of aromatic carbon atoms and the aromatic carbon atoms that form poly-condensed structures. A value of 0 denotes the absence of a condensation center, while a value of 0.7 accounts for structures that are highly condensed [49]. In this regard, both samples present aromatic structures that are slightly condensed due to their low value of $\phi$. Overall, the presence of this wide variety of functional groups detected by means of ${ }^{1} \mathrm{H}$ and ${ }^{13} \mathrm{C}$ NMR will significantly influence the combustion properties of TPO and TPO $[\mathrm{CaO}]$ and eventually, their gaseous and particulate matter emissions. For instance, paraffinic $\mathrm{CH}_{2}$ groups seem to have a positive effect on DCN [91]. Likewise, aromatic rings tend to reduce the DCN more than other functional groups [6].

\section{Conclusions}

This study reported the structural characterization of TPO and TPO $[\mathrm{CaO}]$ produced in a lab-scale twin-auger reactor, utilizing advanced analytical techniques such as APPI FT-ICR MS and ${ }^{1} \mathrm{H}$ and ${ }^{13} \mathrm{C}$ NMR. Physical and chemical properties, including density, viscosity, heating value, and elemental composition of both fuels render TPO and TPO $[\mathrm{CaO}]$ suitable to be implemented without requiring significant modifications in conventional combustion systems. The APPI FT-ICR MS of TPO and TPO $[\mathrm{CaO}]$ recorded ions in the mass to charge ratio $(\mathrm{m} / \mathrm{z})$ range of 200 - 800 and 200 - 750, respectively. The chemical formulas assigned to each resolved peak showed that the main molecular classes in TPO and TPO[CaO] are $\mathrm{HC}$ and $\mathrm{S}_{1}$. $\mathrm{HC}$ was found higher in 
$\mathrm{TPO}[\mathrm{CaO}](78.64 \%)$ than in TPO $(74.91 \%)$, while the $\mathrm{S}_{1}$ class was slightly more abundant in TPO $(14.27 \%)$ than TPO[CaO] (13.9\%). Molecules containing two sulfur atoms $\left(\mathrm{S}_{2}\right)$ were detected in TPO $(0.43 \%)$, but not in $\mathrm{TPO}[\mathrm{CaO}]$. The significant presence of $\mathrm{S}_{1}$ compounds could mean that the core skeletal structures of the molecules might be thiophenic or thiolic in nature. $\mathrm{HC}$ compounds in TPO and TPO $[\mathrm{CaO}]$ were found mainly in the form of tri-aromatics (26\%), tetra-aromatics (13 and 15\%), and penta-aromatics (22 and $30 \%$ ), while $\mathrm{S}_{1}$ compounds in the form of dibenzothiophene (31\%) and benzonaphthothiophene (34\%), which confirms the aromatic nature of both fuels. According to these results, oxidative desulfurization could be more suitable than hydrodesulfuriztion for TPO, considering its higher selectivity in removing aromatic sulfur compounds compared to other techniques such as hydrodesulfurization. Alternatively, due to the complexity of TPO and wide carbon number range $\left(\mathrm{C}_{6}-\mathrm{C}_{56}\right)$, separating it into distinct fractions by distillation can expand the range of possibilities and feasibility in specific applications. In addition, considering the high molecular weight of sulfur containing compounds (determined by FT-ICR MS), distillation can concentrate these compounds in the leftover heavy fraction, improving the characteristic of the other ones. Even though FT-ICR MS did not report saturated hydrocarbons, NMR data revealed the significant presence of paraffinic hydrogen and carbon atoms in both samples. This can be explained by the inability of alkanes to form stabilized ions using APPI ionization. According to ${ }^{1} \mathrm{H}$ NMR, around $80 \%$ of the hydrogen atoms contained in both fuels are present in methylene $\left(\mathrm{CH}_{2}\right)$, methyl $\left(\mathrm{CH}_{3}\right)$, naphthenic, and aromatic groups. Similarly, ${ }^{13} \mathrm{C}$ NMR revealed that carbon atoms in paraffinic groups, including both $\mathrm{CH}_{2}$ and $\mathrm{CH}_{3}$, and protonated carbons in aromatic structures together form more than $50 \%$ of the carbon atoms in TPO and TPO[CaO]. Overall, the present work presents novel insights into the detailed composition and structure of TPO, in order to provide a comprehensive understanding of the fuel, which can be used to better understand its combustion properties.

\section{Acknowledgements}

The authors would like to express their gratitude to COLCIENCIAS for the financial support to research project 1210-715-51742. F. Campuzano acknowledges COLCIENCIAS for the PhD scholarship 757-2016. F. Campuzano also expresses his gratitude to the Clean Combustion Research Center at the King Abdullah 
University of Science and Technology (KAUST) for the research internship. This research used resources of the

Core Labs of KAUST.

\section{References}

[1] V.K. Sharma, F. Fortuna, M. Mincarini, M. Berillo, G. Cornacchia, Disposal of waste tyres for energy recovery and safe environment, Appl. Energy. 65 (2000) 381-394.

[2] Y. Zhang, D. Duan, H. Lei, E. Villota, R. Ruan, Jet fuel production from waste plastics via catalytic pyrolysis with activated carbons, Appl. Energy. 251 (2019) 113337.

[3] K.B. Park, Y.S. Jeong, B. Guzelciftci, J.S. Kim, Two-stage pyrolysis of polystyrene: Pyrolysis oil as a source of fuels or benzene, toluene, ethylbenzene, and xylenes, Appl. Energy. 259 (2020) 114240.

[4] S. van Dyk, J. Su, J.D. McMillan, J. Saddler, Potential synergies of drop-in biofuel production with further co-processing at oil refineries, Biofuel Bioprod. Biorefinering. 13 (2019) 760-775.

[5] A.K. Hailey, J.C. Meerman, E.D. Larson, Y.L. Loo, Low-carbon "drop-in replacement" transportation fuels from non-food biomass and natural gas, Appl. Energy. 183 (2016) 1722-1730.

[6] A.G. Abdul Jameel, N. Naser, A.H. Emwas, S. Dooley, S.M. Sarathy, Predicting fuel ignition quality using 1H NMR spectroscopy and multiple linear regression, Energy Fuels. 30 (2016) 9819-9835.

[7] B. Heuser, M. Jakob, F. Kremer, S. Pischinger, Tailor-Made Fuels from Biomass: Influence of molecular structures on the exhaust gas emissions of compression ignition engines, SAE Int. 36 (2013) 1-17.

[8] P. Hellier, M. Talibi, A. Eveleigh, N. Ladommatos, An overview of the effects of fuel molecular structure on the combustion and emissions characteristics of compression ignition engines, J. Automob. Eng. 232 (2018) 90-105.

[9] A.M. Pourkhesalian, S. Stevanovic, F. Salimi, M.M. Rahman, H. Wang, P.X. Pham, S.E. Bottle, A.R. Masri, R.J. Brown, Z.D. Ristovski, Influence of fuel molecular structure on the volatility and oxidative potential of biodiesel particulate matter, Environ. Sci. Technol. 48 (2014) 12577-12585.

[10] J.D. Martínez, M. Lapuerta, R. Garcia-Contreras, R. Murillo, T. García, Fuel properties of tire pyrolysis liquid and its blends with diesel fuel, Energy Fuels. 27 (2013) 3296-3305.

[11] J.D. Martínez, N. Puy, R. Murillo, T. García, M.V. Navarro, A.M. Mastral, Waste tyre pyrolysis - A review, Renew. Sustain. Energy Rev. 23 (2013) 179-213.

[12] A. Queck, R. Balasubramanian, Liquefaction of waste tires by pyrolysis for oil and chemicals - A review, J. Anal. Appl. Pyrolysis. 101 (2013) 1-16.

[13] G. Choi, S. Oh, J. Kim, Clean pyrolysis oil from a continuous two-stage pyrolysis of scrap tires using in-situ and ex-situ desulfurization, Energy. 141 (2017) 2234-2241.

[14] I. Hita, M. Arabiourrutia, M. Olazar, J. Bilbao, J. M. Arandes, and P. Castaño, Opportunities and barriers for producing high quality fuels from the pyrolysis of scrap tires, Renew. Sustain. Energy Rev. 56 (2016) 745759.

[15] P.T. Williams, Pyrolysis of waste tyres: A review, Waste Manag. 33 (2013) 1714-1728.

[16] J.D. Martínez, Á. Ramos, O. Armas, R. Murillo, T. García, Potential for using a tire pyrolysis liquid-diesel fuel blend in a light duty engine under transient operation, Appl. Energy. 130 (2014) 437-446.

[17] P.T. Williams, S. Besler, D.T. Taylor, The pyrolysis of scrap automotive and heating rate on product composition, Fuel. 69 (1990) 1474-1482.

[18] J. Alvarez, G. Lopez, M. Amutio, N.M. Mkhize, B. Danon, P. Van Der Gryp, Evaluation of the properties of tyre pyrolysis oils obtained in a conical spouted bed reactor, Energy. 128 (2017) 463-474. 
[19] S. Chen, H. Su, J. Chang, W. Lee, K. Huang, L. Hsieh, Y. Huang, W. Lin, C. Lin, Emissions of polycyclic aromatic hydrocarbons (PAHs) from the pyrolysis of scrap tires, Atmos. Environ. 41 (2007) 1209-1220.

[20] S.H. Cho, J.I. Oh, S. Jung, Y.K. Park, Y.F. Tsang, Y.S. Ok, E.E. Kwon, Catalytic pyrolytic platform for scrap tires using CO2 and steel slag, Appl. Energy. 259 (2020) 114164.

[21] P. Parthasarathy, H.S. Choi, H.C. Park, J.G. Hwang, H.S. Yoo, B.K. Lee, M. Upadhyay, Influence of process conditions on product yield of waste tyre pyrolysis-A review, Korean J. Chem. Eng. 33 (2016) 2268-2286.

[22] M. Arabiourrutia, G. Lopez, M. Artetxe, J. Alvarez, J. Bilbao, M. Olazar, Waste tyre valorization by catalytic pyrolysis - A review, Renew. Sustain. Energy Rev. 129 (2020) 109932.

[23] M. Olazar, R. Aguado, M. Arabiourrutia, G. Lopez, A. Barona, J. Bilbao, Catalyst effect on the composition of tire pyrolysis products, Energy Fuels. 22 (2008) 2909-2916.

[24] G. Lopez, M. Olazar, R. Aguado, G. Elordi, M. Amutio, M. Artetxe, J. Bilbao, Vacuum pyrolysis of waste tires by continuously feeding into a conical spouted bed reactor, Ind. Eng. Chem. Res. 49 (2010) 8990-8997.

[25] G. Lopez, J. Alvarez, M. Amutio, N.M. Mkhize, B. Danon, P. van der Gryp, J.F. Görgens, J. Bilbao, M. Olazar, Waste truck-tyre processing by flash pyrolysis in a conical spouted bed reactor, Energy Convers. Manag. 142 (2017) 523-532.

[26] A.G. Abdul Jameel, N. Naser, G. Issayev, J. Touitou, M.K. Ghosh, A.H. Emwas, A. Farooq, S. Dooley, S.M. Sarathy, A minimalist functional group (MFG) approach for surrogate fuel formulation, Combust. Flame. 192 (2018) 250-271.

[27] S.A. Shedid, A.Y. Zekri, Formation damage due to sulfur deposition in porous media, in: Int. Symp. Exhib. Form. Damage Control, Lafayette, Louisiana, 2002: pp. 201-212.

[28] A.G. Abdul Jameel, A functional group approach for predicting fuel properties, King Abdullah University of Science and Technology, KSA, 2019. https://doi.org/10.25781/KAUST-ZBB21.

[29] J.L. Wen, S.L. Sun, T.Q. Yuan, F. Xu, R.C. Sun, Understanding the chemical and structural transformations of lignin macromolecule during torrefaction, Appl. Energy. 121 (2014) 1-9.

[30] K. Dussan, S.H. Won, A.D. Ure, F.L. Dryer, S. Dooley, Chemical functional group descriptor for ignition propensity of large hydrocarbon liquid fuels, Proc. Combust. Inst. 37 (2019) 5083-5093.

[31] J.C. Poveda, D.R. Molina, Average molecular parameters of heavy crude oils and their fractions using NMR spectroscopy, J. Pet. Sci. Eng. 84-85 (2012) 1-7.

[32] M. Hechinger, W. Marquardt, Targeted QSPR for the prediction of the laminar burning velocity of biofuels, Comput. Chem. Eng. 34 (2010) 1507-1514.

[33] D.A. Saldana, L. Starck, P. Mougin, B. Rousseau, L. Pidol, N. Jeuland, B. Creton, Flash point and cetane number predictions for fuel compounds using quantitative structure property relationship (QSPR) methods, Energy Fuels. (2011) 3900-3908.

[34] B. Creton, C. Dartiguelongue, T. de Bruin, H. Toulhoat, Prediction of the cetane number of diesel compounds using the quantitative structure property relationship, Energy Fuels. (2010) 5396-5403.

[35] Y. Han, Y. Zhang, C. Xu, C.S. Hsu, Molecular characterization of sulfur-containing compounds in petroleum, Fuel. 221 (2018) 144-158.

[36] M. Banar, V. Akyıldız, A. Özkan, Z. Çokaygil, Ö. Onay, Characterization of pyrolytic oil obtained from pyrolysis of TDF (Tire Derived Fuel), Energy Convers. Manag. 62 (2012) 22-30.

[37] A. Mohan, S. Dutta, V. Madav, Characterization and upgradation of crude tire pyrolysis oil (CTPO) obtained from a rotating autoclave reactor, Fuel. 250 (2019) 339-351.

[38] B. Acevedo, C. Barriocanal, Fuel-oils from co-pyrolysis of scrap tyres with coal and a bituminous waste. Influence of oven configuration, Fuel. 125 (2014) 155-163.

[39] J.D. Martínez, A. Veses, A.M. Mastral, R. Murillo, M.V. Navarro, N. Puy, A. Artigues, J. Bartrolí, T. García, Co-pyrolysis of biomass with waste tyres: Upgrading of liquid bio-fuel, Fuel Process. Technol. 119 (2014) 
263-271.

[40] F. Xian, C.L. Hendrickson, A.G. Marshall, High resolution mass spectrometry, Anal. Chem. 84 (2012) 708719.

[41] N. Hourani, H. Muller, F.M. Adam, S.K. Panda, M. Witt, A.A. Al-Hajji, S.M. Sarathy, Structural level characterization of base oils using advanced analytical techniques, Energy Fuels. 29 (2015) 2962-2970.

[42] A.M. Elbaz, A. Gani, N. Hourani, A.H. Emwas, S.M. Sarathy, W.L. Roberts, TG/DTG, FT-ICR mass spectrometry, and NMR spectroscopy study of heavy fuel oil, Energy Fuels. 29 (2015) 7825-7835.

[43] H. Chen, R.K. Nelson, R.F. Swarthout, G. Shigenaka, A.H.B. De Oliveira, C.M. Reddy, A.M. Mckenna, Detailed compositional characterization of the 2014 Bangladesh furnace oil released into the world 's largest mangrove forest, Energy Fuels. 32 (2018) 3232-3242.

[44] Z. Wu, R.P. Rodgers, A.G. Marshall, ESI FT-ICR mass spectral analysis of coal liquefaction products, Fuel. 84 (2005) 1790-1797.

[45] F.J. Liu, G.H. Liu, K.A.M. Gasem, B. Xu, A. Goroncy, M.C. Tang, Z.X. Huang, M. Fan, X.Y. Wei, Green and efficient two-step degradation approach for converting Powder River Basin coal into fuels/chemicals and insights into their chemical compositions, Appl. Energy. 264 (2020) 114739.

[46] F. Cheng, Z. Cui, L. Chen, J. Jarvis, N. Paz, T. Schaub, N. Nirmalakhandan, C.E. Brewer, Hydrothermal liquefaction of high- and low-lipid algae: Bio-crude oil chemistry, Appl. Energy. 206 (2017) 278-292.

[47] O.A. Kuti, S.Y. Yang, N. Hourani, N. Naser, W.L. Roberts, S.H. Chung, S.M. Sarathy, A fundamental investigation into the relationship between lubricant composition and fuel ignition quality, Fuel. 160 (2015) 605-613.

[48] A.G. Abdul Jameel, S.M. Sarathy, Lube products: Molecular characterization of base oils, Encycl. Anal. Chem. Appl. Theory Instrum. (2018) 1-14.

[49] A.G. Abdul Jameel, A.M. Elbaz, A.H. Emwas, W.L. Roberts, S.M. Sarathy, Calculation of average molecular parameters, functional groups, and a surrogate molecule for heavy fuel oils using $1 \mathrm{H}$ and $13 \mathrm{C}$ nuclear magnetic resonance spectroscopy, Energy Fuels. 30 (2016) 3894-3905.

[50] A.G. Abdul Jameel, V. Van Oudenhoven, A.H. Emwas, S.M. Sarathy, Predicting octane number using nuclear magnetic resonance spectroscopy and artificial neural networks, Energy Fuels. 32 (2018) 6309-6329.

[51] J.D. Martínez, F. Campuzano, N. Cardona-uribe, C.N. Arenas, D. Muñoz-lopera, Waste tire valorization by intermediate pyrolysis using a continuous twin-auger reactor : Operational features, Waste Manag. 113 (2020) 404-412.

[52] W. Zhang, K. Müllen, Analyzing solid fossil-fuel pitches by a combination of Soxhlet extraction and Fourier transform ion cyclotron resonance mass spectrometry, Carbon N. Y. 167 (2020) 414-421.

[53] A. Gani, A. Jameel, A. Khateeb, A.M. Elbaz, A. Emwas, Characterization of deasphalted heavy fuel oil using APPI (+) FT-ICR mass spectrometry and NMR spectroscopy, Fuel. 253 (2019) 950-963.

[54] A.G. Abdul Jameel, Y. Han, O. Brignoli, S. Telalovic, A.M. Elbaz, H.G. Im, W.L. Roberts, M.S. Sarathy, Heavy fuel oil pyrolysis and combustion: Kinetics and evolved gases investigated by TGA-FTIR, J. Anal. Appl. Pyrolysis. 127 (2017) 183-195.

[55] The Marine Environmental Commite, Resolution MEPC.320(74)-Annex 14, (2019) 1-19.

[56] R. Serefentse, W. Ruwona, G. Danha, E. Muzenda, A review of the desulphurization methods used for pyrolysis oil A review of the desulphurization methods used for pyrolysis oil, Procedia Manuf. 35 (2019) 762768.

[57] S. Ahmad, M.I. Ahmad, K. Naeem, M. Humayun, S. Zaeem, F. Faheem, Oxidative desulfurization of tire pyrolysis oils, Chem. Ind. Chem. Eng. Q. 22 (2016) 249-254.

[58] O. Dogan, M.B. Celik, B. Ozdalyan, The effect of tire derived fuel/diesel fuel blends utilization on diesel engine performance and emissions, Fuel. 95 (2012) 340-346. 
[59] A. Al-lal, D. Bolonio, A. Llamas, M. Lapuerta, L. Canoira, Desulfurization of pyrolysis fuels obtained from waste: Lube oils, tires and plastics, Fuel. 150 (2015) 208-216.

[60] H. Aydin and C. Ilkılıç, Optimization of fuel production from waste vehicle tires by pyrolysis and resembling to diesel fuel by various desulfurization methods, Fuel. 102 (2012) 605-612.

[61] I. Hita, A. Gutiérrez, M. Olazar, J. Bilbao, J.M. Arandes, P. Castaño, Upgrading model compounds and scrap tires pyrolysis oil (STPO) on hydrotreating NiMo catalysts with tailored supports, Fuel. 145 (2015) 158-169.

[62] N. Jantaraksa, P. Prasassarakich, P. Reubroycharoen, N. Hinchiranan, Cleaner alternative liquid fuels derived from the hydrodesulfurization of waste tire pyrolysis oil, Energy Convers. Manag. 95 (2015) 424-434.

[63] D. Debek and J. Walendziewski, Hydrorefining of oil from pyrolysis of whole tyres for passenger cars and vans, Fuel. 159 (2015) 659-665.

[64] I. Hita, E. Rodríguez, M. Olazar, J. Bilbao, J.M. Arandes, P. Castaño, Prospects for obtaining high quality fuels from the hydrocracking of a hydrotreated scrap tires pyrolysis oil, Energy Fuels. 29 (2015) 5458-5466.

[65] S. Ucar, S. Karagoz, J. Yanik, M. Yuksel, M. Saglam, Upgrading scrap tire derived oils using activated carbon supported metal catalysts, Energy Sources, Part A. 29 (2007) 425-437.

[66] Y. Han, F. Stankovikj, M. Garcia-Perez, Co-hydrotreatment of tire pyrolysis oil and vegetable oil for the production of transportation fuels, Fuel Process. Technol. 159 (2017) 328-339.

[67] N.A. Dung, S. Wongkasemjit, S. Jitkarnka, Effects of pyrolysis temperature and Pt-loaded catalysts on polararomatic content in tire-derived oil, Appl. Catal. B Environ. 91 (2009) 300-307.

[68] M.R. Khan, Compositional changes in the mild gasification liquids produced in the presence of calcium compounds, Fuel Process. Technol. 27 (1991) 83-94.

[69] J. Yongbin, H. Jiejie, W. Yang, Effects of calcium oxide on the cracking of coal tar in the freeboard of a fluidized bed, Energy Fuels. 18 (2004) 1625-1632.

[70] Y. Wang, R. Zhao, C. Zhang, G. Li, J. Zhang, F. Li, The investigation of reducing PAHs emission from coal pyrolysis by gaseous catalytic cracking, Sci. World J. 2014 (2014) 1-6.

[71] Q. Wang, X. Zhang, S. Sun, Z. Wang, D. Cui, Effect of $\mathrm{CaO}$ on pyrolysis products and reaction mechanisms of a corn stover, ACS Omega. 5 (2020) 10276-10287.

[72] C.A. Moses, H.L. Bernstein, Fuel specifications for biomass pyrolysis liquids to be used in stationary gas turbines, in: Am. Soc. Mchanical Eng., Birmingham, UK, 1996: pp. 1-14.

[73] G. Juste López, J.J. Salvá Monfort, Preliminary test on combustion of wood derived fast pyrolysis oils in a gas turbine combustor, Biomass Bioenergy. 19 (2000) 119-128.

[74] Petroleum, API gravity, (2015). http://www.petroleum.co.uk/api (accessed November 8, 2019).

[75] Y. Qian, J. Wang, Z. Li, C. Jiang, Z. He, L. Yu, X. Lu, Improvement of combustion performance and emissions in a gasoline direct injection (GDI) engine by modulation of fuel volatility, Fuel. 268 (2020) 117369.

[76] C. Sun, D. Kang, S. V Bohac, A.L. Boehman, Impact of fuel and injection timing on partially premixed charge compression ignition combustion, (2016).

[77] T. Tzanetakis, Spray combustion characterization and emissions of a wood derived fast pyrolysis liquidethanol blend in a pilot stabilized swirl burner, Ph.D. Thesis, University of Toronto, Toronto, Canada, 2011.

[78] P.T. Williams, P. Bottrill, Sulfur-polycyclic aromatic hydrocarbons in tyre pyrolysis oil, Fuel. 74 (1995) 736742.

[79] P. Rathsack, M. Kroll, A. Rieger, R. Haseneder, D. Gerlach, J. Repke, M. Otto, Analysis of high molecular weight compounds in pyrolysis liquids from scrap tires using Fourier transform ion cyclotron resonance mass spectrometry, J. Anal. Appl. Pyrolysis. 107 (2014) 142-149.

[80] H. Wang, X. Chu, Z.-X. Zhao, X.-S. He, Y.-L. Guo, Analysis of low molecular weight compounds by MALDIFTICR-MS, J. Chromatogr. B. 879 (2011) 1166-1179. 
[81] S. Dooley, S.H. Won, J. Heyne, T.I. Farouk, Y. Ju, F.L. Dryer, K. Kumar, X. Hui, C.J. Sung, H. Wang, M.A. Oehlschlaeger, V. Iyer, S. Iyer, T.A. Litzinger, R.J. Santoro, T. Malewicki, K. Brezinsky, The experimental evaluation of a methodology for surrogate fuel formulation to emulate gas phase combustion kinetic phenomena, Combust. Flame. 159 (2012) 1444-1466.

[82] P.T. Cherop, S.L. Kiambi, P. Musonge, Modelling and optimisation of oxidative desulphurisation of oil via central central composite design approach, Green Process Synth. 8 (2019) 451-463.

[83] R.L. Ware, S.M. Rowland, R.P. Rodgers, A.G. Marshall, Advanced chemical characterization of pyrolysis oils from land fill waste, recycled plastics, and forestry residue, Energy Fuels. 31 (2017) 8210-8216.

[84] S.E. Bell, R.G. Ewing, G.A. Eiceman, Atmospheric pressure chemical ionization of alkanes, alkenes, and cycloalkanes, J. Am. Soc. Mass Spectrom. 5 (1994) 177-185.

[85] D.T. Tran, J.M. Palomino, S.R.J. Oliver, Desulfurization of JP-8 jet fuel: Challenges and adsorptive materials, RSC Adv. 8 (2018) 7301-7314.

[86] M.N. Hossain, H.C. Park, H.S. Choi, A comprehensive review on catalytic oxidative desulfurization of liquid fuel oil, Catalysts. 9 (2019) 1-12.

[87] F. Adam, H. Muller, A. Al-Hajji, A. Bourane, O. Koseoglu, Oxidative desulfurization process monitoring using comprehensive two-dimensional gas chromatography and fourier transform ion cyclotron resonance mass spectrometry, Energy Fuels. 29 (2015) 2312-2318.

[88] K. Ding, Z. Zhong, B. Zhang, Z. Song, X. Qian, Pyrolysis characteristics of waste tire in an analytical pyrolyzer coupled with gas chromatography/mass spectrometry, Energy Fuels. 29 (2015) 3181-3187.

[89] J. Udomsirichakorn, P. Basu, P.A. Salam, B. Acharya, Effect of $\mathrm{CaO}$ on tar reforming to hydrogen-enriched gas with in-process $\mathrm{CO} 2$ capture in a bubbling fluidized bed biomass steam gasifier, Int. J. Hydrogen Energy. 38 (2013) 14495-14504.

[90] B.S. Greensfelder, H.H. Voge, G.M. Good, Catalytic and thermal cracking of pure hydrocarbons: Mechanisms of reaction, Ind. Eng. Chem. 41 (1949) 2573-2584.

[91] N. Naser, A. Gani, A.G. Abdul Jameel, A.-H. Emwas, E. Singh, S.H. Chung, S.M. Sarathy, The influence of chemical composition on ignition delay times of gasoline fractions, Combust. Flame. 209 (2019) 418-429. 